\title{
La enseñanza del Derecho en el Perú: cambios, resistencias y continuidades ${ }^{* * *}$
}

Gorki Gonzales Mantilla

\section{Presentación}

El presente trabajo pretende identificar los rasgos característicos de la enseñanza del derecho en el Perú. No se pierde de vista en esta aproximación a los actores que confluyen en su desarrollo: alumnos y profesores. Sin embargo, el cuadro descrito adquiere sentido solo cuando se vislumbra entretejido con la dinámica de los cambios sociales. Las facultades de derecho y su relación con el medio, constituyen un punto de mira no desdeñable, si se trata de entender el sentido que adquiere la enseñanza del derecho. Un proceso heterogéneo de cambios, que lleva consigo resistencias pero también continuidades.

La enseñanza del derecho - en líneas generales- busca proveer herramientas, afinar destrezas y propiciar competencias, identificadas por una perspectiva comprehensiva y un discurso útil para justificar el quehacer de los abogados, el cual es fácilmente reconocible como instrumento básico para la constitución de intereses y posiciones de poder "legítimos» en la sociedad. Por ello, la forma que adquiere la educación legal —es decir, el conocimiento que se imparte y el modo a través del cual se produce la

* Trabajo presentado al Seminário sobre Educacao Juridica realizado del 15 al 17 de febrero de 2003, en la ciudad de Petrópolis- Brasil. El texto forma parte de un volumen de próxima publicación, cuya edición está a cargo de los profesores Rogelio Pérez Perdomo (Venezuela) y Eliane Junqueira (Brasil).

$\left.{ }^{* *}\right)$ Este trabajo no hubiera sido posible sin la colaboración de César Sotomayor Teves, Luciano López y Betzabé Marciani. Tuve, además, el apoyo oportuno y siempre generoso de Jean Carlo Serván. 
interacción pedagógica - puede ser considerada como un indicador del modo como está hecha la textura social.

El estudio aquí propuesto intenta establecer las líneas generales de la enseñanza del derecho en el Perú a comienzos del siglo XXI, sin pasar por alto lo ocurrido en los años previos, fundamentalmente en lo referido a algunos de sus indicadores fundamentales. Quizá uno de los principales problemas de la investigación y, por ello, una de sus limitaciones, ha sido el acceso a la información. En general, las entidades oficiales como la Asamblea Nacional de Rectores o el propio Instituto Nacional de Estadística e Informática, carecen de publicaciones en las que se haga referencia específica a las facultades de derecho. Y en realidad, la documentación sobre la educación superior tampoco es muy precisa. Por esta razón, una parte importante de los datos que han permitido articular los principales indicadores de la educación legal, está construida a partir de los listados o boletines anuales que se encuentran en los archivos de la Asamblea Nacional de Rectores (ANR), en los informes que cada universidad envía anualmente a la ANR, y en situaciones extremas, la información se obtuvo pidiéndola directamente a cada una de las universidades, no siempre con la misma fortuna en todos los casos.

Es preciso indicar que cuando se hace referencia al problema de la enseñanza del derecho en el Perú, el tema resulta inevitablemente monopolizado por la intensa experiencia que la Pontificia Universidad Católica del Perú ha tenido en esta materia. Adquiere sentido, por ello, el que ésta aparezca como un dato central en el trabajo, a partir de la reconstrucción del proceso gestado en los ańos sesenta, como momento de ruptura con el pasado y como punto de partida para el desarrollo de un discurso y un tipo de práctica reformista en la enseñanza.

Explorar el impacto de la formación legal en el desarrollo de la actividad profesional, es una tarea fundamental, pero ello supone configurar los indicadores de este importante espacio de la vida institucional del país que por el momento no existen. Queda, por ello, como una tarea pendiente y una necesidad hacia el futuro.

La parte final del trabajo está dedicada a formular un conjunto de reflexiones, que tienen como punto de apoyo los "hallazgos» de la investigación, pero que dejan tras de sí, otras interrogantes vinculadas a las oportunidades y limitaciones de la reforma de la enseñanza del derecho. 


\section{La enseñanza del derecho en un escenario de cambios}

La enseñanza del derecho en el Perú se ha movido históricamente en un escenario de tensiones entre la tradición y el cambio. En efecto, la estructura de los programas de educación legal en el país, ha estado siempre dominada por una férrea perspectiva más atenta al orden de los códigos que a la dinámica social. El punto de mayor tensión en la segunda mitad del siglo XX parece ubicarse en la década de los años sesenta, un período que articula un nuevo mapa institucional y social en el Perú, producto de los acelerados cambios de los años previos y de las transformaciones que en el país se produjeron. ${ }^{1}$

Sin embargo, a contracorriente, como advierte un diagnóstico sobre la educación legal del año de 1965, los sistemas de enseñanza del derecho en el país, obedecen a un plan anacrónico que no responde a los requerimientos de la época, «en un mundo influido por una portentosa revolución técnica y convulso por un proceso de profundas transformaciones sociales y económicas». ${ }^{2}$ La desvinculación entre la enseñanza del derecho y las demandas de la realidad fue una constante que volvió a ponerse en evidencia en un estudio realizado sobre la situación de los abogados egresados de la Pontificia Universidad Católica del Perú, cinco años después; donde se concluye que los abogados de dicha universidad «configuran un sector profesional vinculado solo parcialmente con los problemas sociales de los sectores sociales nacionales mayoritarios». ${ }^{3}$

1 Sinesio López, «Estado, régimen político e institucionalidad en el Perú (1950-1994)» en: Gonzalo Portocarrero y Marcel Valcárcel (Editores), El Perú frente al siglo XXI; Fondo Editorial PUCP, Lima, 1995, p. 549.

2 «En el caso de la Pontificia Universidad Católica — se afirma en el diagnóstico- los sistemas de enseñanza del derecho no han variado desde su fundación en 1917». El informe corresponde al estudio sobre la enseñanza del derecho, con miras a su eventual reforma, encargado por la Facultad de Derecho de la PUCP, al profesor Carlos Fernández Sessarego. Puede verse, sobre el particular, Carlos Fernández Sessarego, "Bases para la Reestructuración Académica de la Facultad de Derecho de la Pontificia Universidad Católican en: Derecho (PUCP), N²6, Fondo Editorial PUCP, Lima, 1968, pp. 103-104.

$3 \mathrm{La}$ afirmación se respalda en la única investigación relativa a la situación profesional del abogado de aquel entonces en el país. El trabajo — según refiere el autor-se hizo sobre la base de una muestra de 217 egresados de la Facultad de Derecho de la PUCP, la misma que constituía el $15 \%$ del universo de egresados (1.459 personas), según el listado respectivo de la Oficina de Promoción y Desarrollo de la Universidad, que contenía información desde 1932. El mismo estudio estimaba que, para el año 1970, en Lima existían unos 
Un escenario de cambios en todo orden acompaña al proceso de la universidad peruana - y por lo tanto, al de la educación legal en el paísa partir de aquel período: de la crisis y la erosión del poder oligárquico a las reformas del régimen militar y a la expansión del Estado en la década de los setenta, y del fracaso de las políticas populistas y liberales (19801985) al colapso institucional provocado por el gobierno aprista (19851990), en esta última década, además, bajo el fenómeno de la violencia política.

En forma paralela, una creciente politización del movimiento estudiantil ${ }^{4}$ acompasado por el incremento de la población universitaria desde comienzos de los años sesenta, produjo una combinación de expectativas y demandas sociales cuyo reflejo, en ciertos períodos, resultó un factor de importancia en la agenda pública y en el proceso de "modernización" del país. ${ }^{5}$ Este cuadro de tensiones en la universidad tuvo como marco legal el provisto por la Ley Universitaria de 1960 (Ley No 13417, de 8 de abril de 1960). Pero no se pierda de vista que, a menos de 10 años de promulgada aquella ley, la Junta Revolucionaria de la Fuerza Armada dictó la Ley Orgánica de la Universidad Peruana (Decreto Ley No 17437), puesta en vigencia en febrero de 1969.

La primera norma, recoge el «restablecimiento del co-gobierno o participación de los estudiantes en la dirección de la universidad», ${ }^{6}$ que amplió enormemente el ámbito de la autonomía universitaria, al remitir muchos aspectos del gobierno de la universidad a lo que se determinara

4,000 abogados en ejercicio. Véase: Lorenzo Zolezzi Ibárcena, La profesión de abogado en Lima (una aproximación empírica), Fondo Editorial PUCP, Lima, 1982, p. 68.

4 Enrique Bernales Ballesteros, Movimientos sociales y movimientos universitarios en el Perú, Pontificia Universidad Católica del Perú-Facultad de Ciencias Sociales, Lima, 1974, p. 44.

5 Como bien apunta Carlos Iván Degregori, «Ayacucho, o más precisamente las provincias norteñas del departamento, presentan como característica peculiar que la punta de lanza de la modernidad no fue alguna empresa industrial o minera, sino una institución teóricamente académica: la universidad, que a partir de 1959 se convirtió en foco dinamizador que podríamos llamar integral, en tanto su influencia abarcó desde la economía hasta la ideología» Carlos Iván Degregori, «Sendero Luminoso: los hondos y mortales desencuentros», en: Eduardo Ballón (Editor), Movimientos sociales y crisis: el caso peruano, Centro de Estudios y Promoción del Desarrollo-DESCO, Lima, 1986, p. 236.

6 René Ortiz Caballero, "Universidad y modernización en el Perú del Siglo XX”, en: Biblioteca de Derecho Político, Fondo Editorial PUCP, Lima, 1998, Vol. III, p. 74. 
en sus correspondientes estatutos. ${ }^{7}$ La segunda, sustrae la autonomía universitaria - a través de la creación del Consejo Nacional de la Universidad Peruana, conformado por autoridades de origen universitario-y restringe el co-gobierno estudiantil. Con este modelo se crea un esquema que inserta el problema de la universidad en el sistema más amplio de reforma de la educación. ${ }^{8}$

En medio de ello, la demanda de los estudios de derecho se incrementó considerablemente, como indicador no solo del crecimiento demográfico sino también del acceso a la educación superior de las grandes mayorías nacionales, y como producto probable de los requerimientos generados por el proceso de modernización del Estado y de la sociedad peruanas. Las cifras que reflejan este incremento sustancial de los estudiantes de derecho en el período comprendido entre 1960 y 1986: de 1,338 postulantes, en 1960, a 37,119 en 1986 (Cuadro No 1).

\section{Cuadro No 1}

Número de postulantes a las facultades de Derecho-Perú (1960-1986)

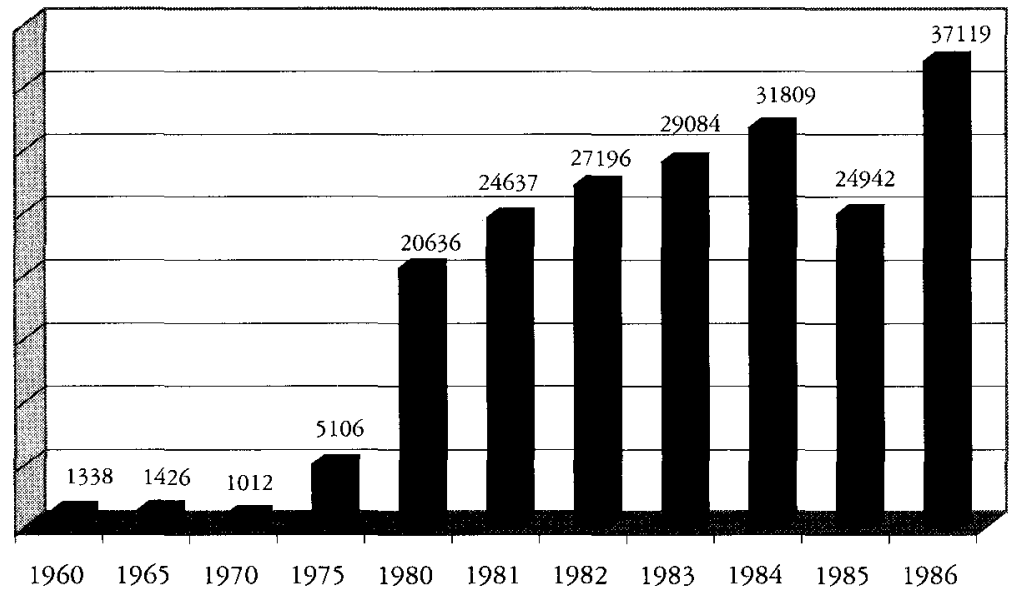

Fuente: Asamblea Nacional de Rectores. Secretaría Ejecutiva de la Comisión de Coordinación Interuniversitaria. Boletín Perú: Estadísticas Universitarias 1960-86. Lima. Año 9. No 10. Junio 1988

\section{Loc. cit.}

8 Enrique Bernales y Marcial Rubio, Perú: Constitución y sociedad política, Desco, Lima, 1981, pp. 198-199. 
En efecto, mientras la población total del país se elevó de 9’900,000 de habitantes, en el año 1960, a 17'300,000, en 1980, y a 22'600,000, en 1990, ${ }^{9}$ casi en el mismo arco temporal, la población global de estudiantes de las universidades del país se multiplicó en catorce veces. Es decir, de 25,748 matriculados en 1960, se pasó a 384,599 en 1986. Yen el caso de la población de las facultades de derecho, las cifras no fueron menos conservadoras: de 3,391 alumnos matriculados en 1960, se multiplicó a 35,503 en 1986, año en el que representaban el $9.23 \%$ del total de la población estudiantil (Cuadro No 2).

\section{Cuadro No 2}

Número de universitarios matriculados y número de alumnos de las facultades de Derecho - Perú (1960-1986)

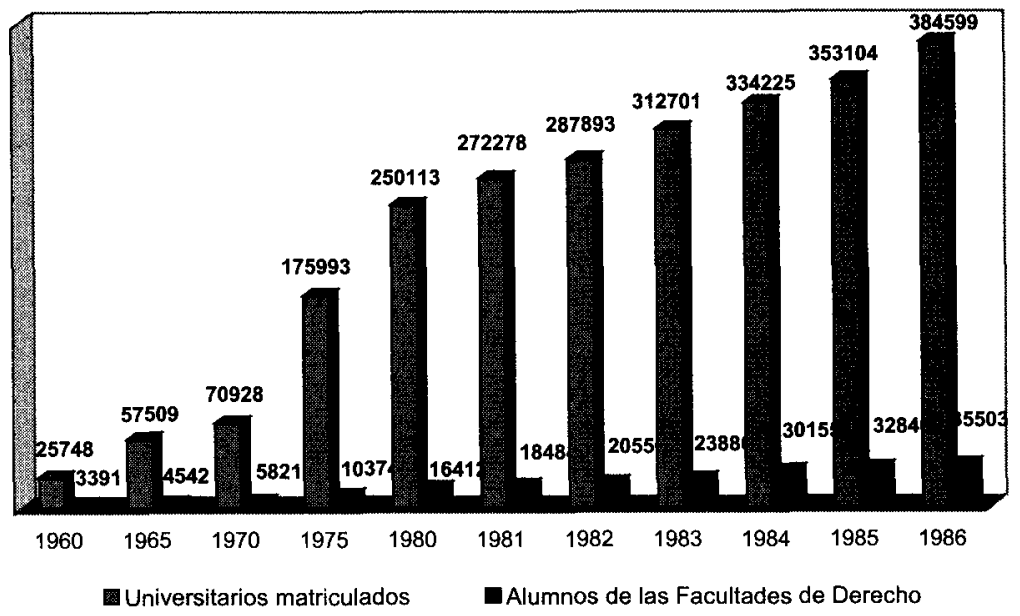

Fuente: Asamblea Nacional de Rectores. Secretaría Ejecutiva de la Comisión de Coordinación Interuniversitaria. Boletín Perú: Estadísticas Universitarias 1960-86. Lima. Año 9. No 10. Junio 1988

1.1 La reforma de la enseñanza del derecho: una experiencia de ruptura con la tradición

No obstante lo expuesto, al parecer, la preocupación por la reforma de la enseñanza del derecho en toda su intensidad corresponde al pasado. ${ }^{10}$

9 Instituto Nacional de Estadística e Informática, Censo de Población 1940. Estimaciones de población 1950-2050 (http://www.inei.gob.pe). 
Como advierte el profesor Felipe González, de la Universidad Diego Portales de Chile, "[...] los intentos de reforma escasamente subsistieron. Existen, por cierto, algunas excepciones, como es el caso de la Pontificia Universidad Católica del Perú, que a partir de esos años ha venido desarrollando y consolidando modalidades de enseñanza del Derecho distintas a las tradicionales en América Latina, pero en la casi totalidad de los casos se volvió a los ejes tradicionales, a veces con pequeños retoques aquí y alláw. ${ }^{11}$ En efecto, hacia finales de la década de los sesenta, un grupo de profesores de la mencionada Casa de Estudios, liderados por su Decano, se propuso la tarea de reformar el sistema de enseñanza en la Facultad de Derecho. ${ }^{12}$ Esta voluntad institucional contó, además, con el auspicio económico de la Fundación Ford, ${ }^{13}$ y con un énfasis cada vez más acen-

10 «Desde los setenta no se trata de la reforma de la enseñanza en las universidades. No se sabe si las facultades de Derecho están produciendo abogados dotados de un mínimo de herramientas para desarrollar un razonamiento jurídico aceptable». Gabriel Ortiz de Zevallos y Pierina Pollarolo (Editores), Task Forces. Agenda para la primera década. Reforma del Poder Judicial, Instituto Apoyo, Lima, 2000, p. 24. Al respecto, se recuerda que la experiencia de la reforma de la enseñanza de la PUCP forma parte de un movimiento generado en distintas universidades de América Latina. Sus resultados inmediatos fueron compartidos en diversos congresos de educación jurídica: «en 1971 en Viña del Mar, Chile; en 1972 en Poona, India; y en 1973 en Lima. En las conferencias de Lima y Viña del Mar fue posible comparar las experiencias de la Universidad Católica del Perú con las reformas análogas introducidas en cinco escuelas de Derecho de Chile, en diversas facultades de Derecho del Brasil, en la mayoría de las escuelas de Derecho de Colombia a través de la institución conocida como ARED (Asociación para la reforma en la enseñanza del Derecho) y en la Universidad de Costa Rica», en: Reforma de la enseñanza e investigación del Derecho, Lima (PUCP), julio de 1973, p. 18.

11 Felipe González, «Evolución y perspectivas de la red universitaria sudamericana de acciones de interés público", en: Defensa Legal del Interés Público. Enseñanza, estrategias, experiencias. Cuadernos de Análisis Jurídico $\mathrm{N}^{\circ} 9$. Universidad Diego Portales-Escuela de Derecho, Santiago de Chile, 1999, p. 36.

12 En el punto de partida de este movimiento se cuenta el viaje de los profesores Carlos Fernández Sessarego, Jorge Avendaño Valdez y Felipe Osterling Parodi a cinco escuelas de leyes de los Estados Unidos: Notre Dame, Harvard, Columbia, Georgetown y New York. Las visitas se produjeron en 1965 y tuvieron por finalidad conocer la orientación profesional, los métodos de enseñanza y los planes de estudio allí establecidos. Véase: Carlos Fernández Sessarego, Felipe Osterling y Jorge Avendaño, «Informe sobre la visita realizada por una comisión de catedráticos de la Facultad a universidades norteamericanas», en: Derecho (PUCP), $\mathrm{N}^{\circ} 2$, Lima, pp. 125-172.

13 Este plan, en un caso sin precedentes -ni réplica- en el país, contó con el auspicio y financiamiento de la Fundación Ford. El proyecto, aprobado en 1968, comprendía cuatro 
tuado en las metodologías de la enseñanza, ha mantenido sus proyecciones hasta la actualidad.

La propuesta de reforma - como se ha dicho- surge en el contexto de cambios profundos en el país. Movilizaciones campesinas, un amplio proceso migratorio y la explosión urbana acecharon el orden imperante y erosionaron la estructura social oligárquica de aquel entonces. Compartiendo el mismo espacio, la universidad se convirtió en un escenario de luchas y escaramuzas precipitadas por el proceso político.

La presión social de este período fue asimilada por las reformas impulsadas por el gobierno del general Juan Velasco Alvarado. Un régimen que, apenas instalado, anticipó su ruptura con el molde de la tradición golpista. El Gobierno Revolucionario de las Fuerzas Armadas hizo saber, desde el inicio, su intención de transformar la estructura del Estado y de modificar el orden social, económico y cultural. Su política se definió, entonces, como nacionalista, independiente y firme en la defensa de la soberanía y la dignidad nacional. ${ }^{14}$

Reformar la enseñanza del derecho significaba producir cambios en un marco de mayores transformaciones en la agenda pública, impregnados por el influjo que éstos traían consigo. El contexto se hacía propicio para "poner al día» el rol de las instituciones jurídicas y de los profesionales del derecho, como respuesta a las demandas sociales y al "desajuste» de las

aspectos: i) Preparación de aproximadamente quince profesores en el extranjero, a través de un programa de cooperación con la Escuela de Derecho de la Universidad de Wisconsin; ii) Estímulo de la investigación jurídica en la Facultad, a cargo preferentemente de los profesores participantes en el programa con la Universidad de Wisconsin; iii) Desarrollo de la biblioteca, incluyendo adquisición de materiales y capacitación de un bibliotecario en el extranjero durante un lapso de diez meses; y vi) Establecimiento de la Oficina de Orientación Profesional, que comprendió la preparación del jefe de dicha Oficina durante una corta visita a diversas facultades de derecho extranjeras. Para la realización del programa se obtuvo de la Fundación el aporte, en calidad de donación y para el período 1968, 1969 y 1970 , del monto de US $\$ 196,000.00$. Esta suma sería incrementada en US $\$ 46,000.00$ al año siguiente. Por su parte, la Universidad se obligó a contribuir, para el mismo período, con el monto de US $\$ 100,000.00$. En total, se hizo una inversión de US $\$ 340.000,00$. Puede verse, sobre el particular, Pontificia Universidad Católica del Perú. «La Marcha del Proyecto Ford», en: Derecho (PUCP), N²8, Lima, 1970, p.112. Asimismo, Fernando de Trazegnies, Jorge Avendaño y Lorenzo Zolezzi, «Nuestra Reforma de la Enseñanza del Derecho", en: Derecho (PUCP), N²9, Lima,1971, p. 132.

14 René Ortiz Caballero, op. cit., p. 74. 
hegemonías internacionales, especialmente en la América Latina de fines de los sesenta. ${ }^{15}$

El mencionado proyecto de reforma de la enseñanza del Derecho ha tenido tres importantes momentos en el tiempo. El primero se reflejó en la propuesta de plan de estudios de Carlos Fernández Sessarego, de 1965. Ésta consideraba una duración de diez ciclos, seis de ellos de formación común y el resto orientado hacia la especialización en siete grandes rubros: Derecho Privado, Ciencias Penales, Derecho Administrativo, Derecho del Trabajo y de la Seguridad Social, Derecho de la Empresa, Derecho del Desarrollo y Derecho Internacional y Diplomático. La propuesta fue objeto de una serie de ajustes, donde los estudiantes jugaron un papel relevante. El segundo momento se produjo con la entrada en vigencia del plan de estudios en 1967, cuya duración fue, sin embargo, efímera. Este plan marcó una notoria diferencia con la tradición previa: además de continuar con la idea de los cursos electivos, se puso énfasis en el método activo y se incorporaron cursos tales como Sociología del Derecho y Metodología del Aprendizaje Jurídico. Tres años después se aprobó un nuevo plan de estudios, que profundizaría las reformas. En esto también tuvo que ver el Decreto Ley No 17437, Ley Universitaria (art. 94º y 95०). No obstante, las críticas a las que quedó sometido este plan, fueron las coordenadas que marcaron la evolución de la reforma en el tiempo.

En su versión fuerte, el movimiento reformista expresaba su disconformidad con el «orden establecidon; sugería, por tanto, la necesidad de cambiar en forma «radical» el modelo de enseñanza en la perspectiva de promover cambios sociales ${ }^{16}$. Una visión de «compromiso con la reali-

15 Como recuerda Lorenzo Zolezzi, en este escenario "[...] muchas fundaciones norteamericanas y organismos internacionales se mostraron dispuestos a apoyar financieramente proyectos ordenados de desarrollo, en los cuales se asignaba un rol importante a las instituciones jurídicas y a los profesionales del Derecho». Lorenzo Zolezzi Ibárcena, «Formación del abogado y sociedad: balance y perspectivas", en: Derecho (PUCP), $N^{\circ} 45$, Lima, p. 457. Es de reconocer, igualmente, que estas iniciativas corresponden a una preocupación más general del gobierno norteamericano por los asuntos latinoamericanos, como resultado de la Revolución Cubana. Véase al respecto, Thomas E. Skindmore, "Studying the History of Latin America: A case of Hemispheric Convergencen, en: Latin America Research Review, Vol. 33, $\mathrm{N}^{\circ} 1,1998$, pp. 105-127.

16 La pregunta que se formulaba en este sentido - a cinco años de iniciado formalmente el proceso de reforma- el doctor Jorge Avendaño Valdez, ex-Decano de la Facultad de Derecho de aquel entonces, parecía crucial: «¿En qué sentido debe cambiarse la educa- 
dad», que prefigura la idea del derecho en cuestión, se ve graficada en una de las posturas más críticas - la del profesor Luis Pásara - como «[...] el enfoque legalista tradicional, que creyó en la existencia del orden jurídico como un mundo autónomo de consistencia propia, con sus propias normas, principios y fines, sustraídos y por encima de las luchas y los enfrentamientos del mundo cotidiano, de la realidad. Esta visión mítica del derecho claramente a-científica creó conceptos y vías metodológicas que no solo no tenían validez teórica sino que cumplieron una función de ocultamiento de la realidad social y económica, al servicio de la cual el derecho tuvo una función instrumental sumamente importantem. ${ }^{17}$

Una reconstrucción aproximada de este panorama «inevitable» —en la versión del profesor Pásara-, se articula, con matices, en el discurso que justifica las causas de la reforma a tres años de su inicio. Se afirmó, entonces, que "los defectos fundamentales del sistema anterior obedecían a un distanciamiento entre la enseñanza universitaria y el ejercicio de las profesiones jurídicas». ${ }^{18}$ Un distanciamiento o, más bien, "ruptura" entre el concepto del derecho y la vida social que en el ámbito de la enseñanza se expresaba en cuatro niveles: i) ruptura entre el carácter teórico de los estudios y las exigencias de la vida práctica del egresado; ii) ruptura entre las especialidades jurídicas cuya formación era encarada por la Escuela de Derecho y las necesidades sociales, de modo que la formación privatista ocupaba un lugar relevante; iii) ruptura entre las aspiraciones al cuestionamiento de las relaciones sociales y un Derecho rígido; y, iv) rup-

ción legal para que efectivamente dé lugar al surgimiento de nuevos abogados para esa nueva sociedad que se requiere? [...]». La respuesta -en palabras del mismo ex-Decano- no era menos dramática: «Hay que aclarar, en primer término, que el cambio en la enseñanza del derecho solo puede calificarse como verdadero cambio cuando sus efectos benefician a todos o a la gran mayoría de miembros de una sociedad. En el caso concreto de un país subdesarrollado los criterios deben establecerse en función del impacto social de sus resultados, y en este sentido no hay cambio si no es un cambio radical. Toda educación legal que sirva a la perpetuación de un orden social injusto, es una educación legal que no ha cambiado realmente, aun cuando parezca avanzada". "Discurso Pronunciado por el doctor Jorge Avendaño Valdez, Pro-Rector de la Pontificia Universidad Católica del Perú» en: II Conferencia sobre la Enseñanza del Derecho y el Desarrollo. Pontificia Universidad Católica del Perú-Programa Académico de Derecho, Lima, 1973, p. 21.

17 Luis Pásara, “QQué enseñar?» en: II Conferencia sobre la Enseñanza del Derecho y el Desarrollo [...], op. cit., p. 74.

18 Fernando de Trazegnies, Jorge Avendaño y Lorenzo Zolezzi, «Nuestra Reforma [...]", op. cit., p. 132. 
tura entre la información recibida en la Escuela de Derecho y la información empleada en la vida profesional. ${ }^{19}$

Paradójicamente, la propuesta de cambio arrastraba consigo un factor de resistencia. Advertido, en su momento, por el profesor De Trazegnies, ${ }^{20}$ el cuestionamiento básico al modelo de educación había concentrado su principal atención en el método, es decir, en los procedimientos empleados para la enseñanza; sin embargo, la crítica a los contenidos, en los hechos, permaneció en un segundo plano. La prioridad de la reforma, atribuida al desarrollo de destrezas y habilidades para el razonamiento legal, supuso que el cambio en la estructura conceptual de los contenidos se produciría más adelante, pero esto no ocurrió: el método no era suficiente como agente de transformación.

\subsection{El «otro derecho» para el cambio}

De este modo, el puente que uniría al derecho con las demandas de la sociedad, en este escenario de ruptura, no tuvo la consistencia esperada. Su estructura se desgastó al poco tiempo de iniciado el proceso de trasformación. El énfasis inicial en el método resultó infructuoso. El "otro derecho", aquel que pudiera resultar de un "enfoque alternativo y competitivo con el tradicional», ${ }^{21}$ no tuvo la presencia necesaria en la pro-

19 Loc. cit.

20 Al respecto, se precisó: “Un cambio radical en los estudiantes de Derecho, se ha dicho, supone la sustitución de la clase magistral por un sistema de enseñanza dialogada que desarrolla mejor las habilidades jurídicas, insiste en la adopción de un razonamiento que permita resolver cualquier problema legal antes que en la divulgación de leyes en estado de permanente cambio...". Y las limitaciones de este tipo de "cambio" se hacen notar con «preguntas tales como ¿de qué sirve a la sociedad que los alumnos se encuentren mejor preparados en el tipo de Derecho que se enseña actualmente? ¿cuál es el papel que cumplirán en la vida social los abogados que estamos formando?, ¿qué tipo de abogados requiere el momento histórico?. [...] Si no resolvemos estas preguntas y nos limitamos a [...] insistir en nuevos métodos de enseñanza con la vista puesta aún en las antiguas concepciones del Derecho, puede producir una crisis mayor que la que el movimiento reformista pretende superar. El papel de las Escuelas de Derecho no se limita a formar simplemente buenos abogados, sino buenos abogados que contribuyan al proceso de cambio hacia un mundo mejor". Fernando de Trazegnies, "La enseñanza del Derecho como actividad subversiva", en: II Conferencia sobre la Enseñanza del Derecho y el Desarrollo, Pontificia Universidad Católica del Perú-Programa Académico de Derecho, Lima, 1973, pp. 48 y 50.

21 Luis Pásara, "¿Qué enseñar?» en: II Conferencia sobre la Enseñanza del Derecho y el Desarrollo, op. cit., p. 73. 
puesta inicial de reforma —o bien se quedó en el discurso-y, quizá, por ello, la fuerza de la teoría legal precedente se mantuvo intocada, en las mismas condiciones.

En la perspectiva del discurso renovador, era preciso afinar el «otro" nuevo derecho y transmitir su sentido al conjunto de la reforma. No cabía por más tiempo prolongar la disociación entre teoría y práctica. En esa dirección, se define el derecho como "un instrumento para la realización de fines sociales y no como un simple ordenamiento formal". Se dijo que el Derecho era un orden social y se plantearon, respecto de la enseñanza, las siguientes tres líneas de principio, que, en buena cuenta, definieron el tercer momento en el proceso de reforma y de su secuela: ${ }^{22}$ i) estudiar el derecho tal como se produce en la sociedad, es decir, a través de los distintos modos en los que se manifiesta y no en abstracto; ii) confrontar el derecho con las demás prácticas sociales para examinar la coherencia de su racionalidad interna en contraste con las exigencias, necesidades y aspiraciones sociales; $y$, iii) Asumido como práctica social, el Derecho evoluciona con la sociedad misma y no es el único orden jurídico posible. No basta, por tanto, explicar el Derecho vigente: es preciso, también, cuestionarlo. ${ }^{23}$

El producto resultó ser un nuevo "currículum de estudios", definido hacia 1970. Articulado por cursos semestrales (divididos en ocho semestres), obligatorios y electivos, con su correlato en un sistema de créditos (ciento cuarenta, para presentarse al grado de abogado). Ese sería el marco de flexibilidad para hacer viable el nuevo concepto de Derecho que se abriría espacio a través de: ${ }^{24}$ i) la incorporación de contenidos y cursos no

22 Fernando de Trazegnies, Jorge Avendaño y Lorenzo Zolezzi, «Nuestra Reforma [...]", op. cit., pp. 135-136.

23 Cabe anotar que esta perspectiva evidencia una nítida influencia de las corrientes críticas del derecho, en particular, aquella identificable en la obra del profesor de la Universidad de Stanford, Lawrence Friedman. El planteamiento central de su obra forma parte de las líneas directrices del discurso reformador. Véase: Lawrence Friedman. The legal system. A Social Science Perspective, Rusell Sage Foundation, New York, 1975, p. 8. Esta afinidad se explica más aún si se tiene presente que en 1969 en la Revista de la Facultad de Derecho de la PUCP, se publicó el artículo titulado «El derecho como instrumento de cambio social», trabajo de Lawrence Friedman en colaboración con Jack Ladinsky. Véase: Derecho. Revista de la Facultad de Derecho de la Pontificia Universidad Católica del Perú, Lima, No XXVII, 1969, p. 22 y ss.

24 Fernando de Trazegnies, Jorge Avendaño y Lorenzo Zolezzi, «Nuestra Reforma $[\ldots] »$, op. cit., p. 139. 
jurídicos, necesarios para explicar las causas y los efectos socio-económicos del derecho; y, ii) la sustitución de la tradicional división de los cursos en función de las leyes o de los libros del Código, por la identificación de los tópicos de la realidad social como punto de partida para la formulación de los mismos.

El cambio no sería posible sin docentes comprometidos con los principios de la reforma. En esa dirección, no se perdió de vista la necesidad de crear condiciones para formar profesores jóvenes - a través de pasantías en universidades norteamericanas-, que luego pudieran incorporarse como docentes a dedicación. El esfuerzo por reestructurar el cuerpo docente de la facultad significó una modificación sustancial en el promedio de edad de los profesores: antes oscilaba entre los 48 y los 50 años; para el año 1971, el promedio de edad no excedía de los 30-32 años. La misma lógica impulsó la necesidad de mejorar los recursos de la biblioteca $a^{25} \mathrm{y}$ crear un espacio institucional de investigación jurídica con una orientación interdisciplinaria para entender la interacción con la realidad. ${ }^{26}$

\subsection{Las limitaciones de la reforma: entre las expectativas y la realidad}

Resistencias de diverso origen estuvieron presentes desde el inicio de este proceso de conversión. En el ámbito interno, fueron los profesores más jóvenes quienes mostraron pronta adhesión. Al parecer, las reservas no tuvieron muchos adeptos, pero apuntaron a la metodología y, en general, al nuevo concepto de derecho, es decir, al corazón de la reforma. Las razones presentes en el imaginario de los opositores eran atribuidas a su "formación tradicional" y a la renuencia al cambio sobre el papel que el abogado debía representar en la sociedad. ${ }^{27}$

La reacción de los estudiantes estuvo delimitada por un atisbo de «infiltración política», derivado, supuestamente, de la aproximación de la

25 Ibid., p. 144.

26 En efecto, el Centro de Investigaciones Jurídicas de la Facultad, quedó a cargo del jurista arequipeño y profesor de Derecho de Familia, Héctor Cornejo Chávez. En: Reforma de la Enseñanza e Investigación del Derecho en la Universidad Católica, PUCP, Lima, julio de 1973, pp.11-12. Cabe reconocer que se trata de un esfuerzo institucional que no ha contado con un apoyo sostenido en el tiempo.

27 Loc. cit. 
reforma del derecho a las ciencias sociales, ${ }^{28}$ tanto como de la supresión de materias tradicionales como el Derecho Romano. En todo caso, a esta percepción se agregaron —en opinión de quienes lideraban la reforma y principalmente para el caso de los alumnos antiguos - tres cosas: ${ }^{29}$ i) el peso de la costumbre y la tradición; ii) la mayor carga de trabajo representada por la exigencia significativa del nuevo plan de estudios; iii) la fuerza de la tradición, reforzada por una visión utilitarista - y lucrativa- de la profesión, disfuncional y resistente a los cambios.

En el ámbito externo, los obstáculos de esta reforma estuvieron inicialmente determinados por la falta de información ${ }^{30}$ respecto del quehacer de los abogados y sobre los factores que influían en el éxito profesional. ${ }^{31}$ Aunque difícil de medir en su momento, se percibía un «mundo

28 Esta acusación, levantada —en opinión de Luis Pásara- por los sectores más conservadores de la Facultad, «[...] consiste en que estaríamos politizando el contenido de los estudios de derecho. Nuestra respuesta también quiere ser muy clara. En efecto, buscamos politizar la enseñanza del derecho, si por politizar se entiende hacer conciente al estudiante de las connotaciones políticas que esencial y fundamentalmente tiene el derecho. Es decir, buscamos hacer explícito el carácter político del derecho a diferencia de la enseñanza tradicional que ocultó expresamente lo que de político tenía el contenido y el funcionamiento del derecho, creando una teoría enmascaradora para este fin, buscando formar profesionales «neutrales" técnicos que podrían tener opciones políticas pero que no comprometieran la "pureza» de lo jurídico». Luis Pásara, “QQué enseñar?» en: II Conferencia $[\ldots]$, op. cit., p. 75 .

29 Fernando de Trazegnies, Jorge Avendaño y Lorenzo Zolezzi, Nuestra Reforma [...], op. cit., pp. 144-145.

30 En respuesta a las críticas, la Facultad de Derecho en julio de 1973, emite un informe - llamado relato cronológico-, de los hechos más saltantes de la reforma. El tono que se emplea es muy revelador de lo que venía ocurriendo en el contexto: «recientemente algunas personas han criticado duramente las reformas introducidas en la enseñanza e investigación del Derecho en la Universidad Católica. Creemos que esta actitud obedece a la ignorancia que existe en relación a este proceso. Por esta razón, se ha preparado un relato cronológico de los hechos más saltantes de la reforma. Esta información va destinada a quienes estén capacitados a comprender este esfuerzo educativo [...]". En: "La reforma en la enseñanza e investigación del derecho en la Universidad Católica», PUCP, Lima, 1973, p. 3.

31 La investigación sobre la situación de los abogados egresados de la Pontificia Universidad Católica del Perú, a cargo de Lorenzo Zolezzi, fue realizada sobre la base de una encuesta entre los años de 1970 y 1971. Su conclusión, sin embargo, tomo algunos años más y, finalmente, su publicación se produjo recién en 1982. Véase: Lorenzo Zolezzi Ibarcena, La profesión de abogado en Lima [...], op. cit. 
laboral» delimitado aún por el influjo de reminiscencias oligárquicas y patriarcales. De este modo, "el éxito en la profesión estaría fuertemente vinculado al origen socio-económico" y reservado al sexo masculino. ${ }^{32}$ Pero al fin y al cabo, esta «realidad» formaba parte del reto que la reforma debía enfrentar.

Nuevos ajustes - cuyos orígenes fueron siempre el debate internose introdujeron en el modelo de 1970, sin que ello significara la prevalencia de la visión reformadora en la enseñanza del derecho. Entre los factores que dieron impulso al afianzamiento de la tradición, quizá se encuentre el debate generado con motivo de la reforma del ordenamiento civil, que concluyera con la promulgación del Código Civil de 1984, teniéndose en cuenta que la mayoría de los integrantes de la comisión reformadora eran docentes de la PUCP. ${ }^{33}$ Eso explica en buena medida la gran difu-

32 Como advierte Lorenzo Zolezzi, apenas el $12 \%$ de los casos entrevistados fueron mujeres. Era posible prever, entonces, una marcada composición masculina del mundo profesional de los abogados. Ibid, p. 34.

33 La Comisión Reformadora del Código Civil se crea por el Decreto Supremo No 095, de 1 de marzo de 1965. Esta norma fue promulgada durante el primer gobierno del presidente Fernando Belaunde, siendo Ministro de Justicia Carlos Fernández Sessarego. Se puede decir que entre quienes la integraron desde un inicio, los que se fueron incorporando, los miembros del cuerpo de asesores, y finalmente los miembros de la Comisión Revisora, siempre hubo una importante mayoría de los profesores de la PUCP:

Profesores de la PUCP: Carlos Fernández Sessarego, Felipe Osterling, Jorge Vega García, Héctor Cornejo Chávez, Ismael Bielich Flórez, Jorge Avendaño Valdez, Fernando Vidal, Fernando de Trazegnies y Manuel de la Puente y Lavalle.

Profesores de la UNMSM: José León Barandiarán, Rómulo Lanatta Guilhem; Jorge Eugenio Castañeda; Max Arias Schereiber; Lucrecia Maisch Von Humboldt.

También formaron parte de la Comisión como presidentes, en sucesivos momentos: Alberto Eguren Bresani y Manuel García Calderón.

Asesores de la Comisión: Carlos Cárdenas Quirós, Sergio León Martínez, Jorge Muñiz Zíches, Delia Revoredo Marsano de Debakey, Rafael Rosselló de la Puente, Jorge Vega Velasco y Shoschana Zusman Tinman. Todos eran profesores de la PUCP.

Comisión Revisora: conformada por la Ley No 23403 del 13 de mayo de 1982 . Tuvo representantes de la Cámara de Diputados, del Senado y del Ministerio de Justicia: de los tres abogados del Ministerio de Justicia, solo dos eran profesores universitarios y ambos de la PUCP: César Fernández Arce y Jack Bigio Chrem.

Fuente: Fernando Vidal Ramírez: «Nota Preliminar» en: Código Civil, Ministerio de Justicia, Edición Oficial; Gaceta Jurídica Editores; tercera edición, Lima, 1996, citas: pp 34-47, texto completo: pp. 13-71. También se han consultado los archivos del Departamento de Derecho de la PUCP. 
sión que, desde fines de los años $70^{\prime}$ y a lo largo de la década de los $80^{\prime}$, se dio a los estudios en derecho civil en la facultad. Muchas publicaciones hicieron su aparición, ${ }^{34}$ dando cuenta de las ponencias de los sucesivos libros del proyecto de código, o bien desde posiciones menos exegéticas y abriendo la discusión en torno a argumentos que -en la mayoría de los casos- parecían más propios del debate codificador europeo. ${ }^{35} \mathrm{La}$ influencia, por momentos «inmanejable», de la doctrina extranjera en el escenario codificador, se revela con suma crudeza si se sigue atentamente la estructura del código producido, repleto de inconexiones, quizás como resultado de visiones compartimentalizadas respecto del propio derecho civil, que habría llevado a sus redactores a repartirse los libros del código y a hacer cada uno, por su lado, lo mejor con la «mejor doctrina» posible. ${ }^{36}$

34 Además de las revistas de estudiantes y de la propia revista de la Facultad de Derecho, que, a veces, dedicaban números íntegros a los tópicos del Derecho Civil, hizo su aparición una colección de libros dedicada a comentar el Código Civil de 1984: La biblioteca Para Leer el Código Civil, publicada por el Fondo Editorial de la PUCP. Entre sus volúmenes destaca, por su versatilidad atenta a los problemas jurídicos a través del análisis de la jurisprudencia en el contexto de realidad social, el trabajo sobre la responsabilidad extracontractual, a cargo del profesor Fernando de Trazegnies Granda.

35 Adquiere sentido lo sostenido por el jurista italiano Rodolfo Sacco, cuando afirma que los cuarenta códigos civiles que entraron en vigencia en el período comprendido entre 1948 y 1988 no resultaron un signo necesario de que todos ellos hubieran sido, en efecro, "nuevos" códigos, pues, en su mayoría, ellos no eran sino imitaciones, en mayor o menor medida revisadas, de modelos vigentes en otros lugares. Citado por Leysser León, «La importancia del derecho comparado en la reforma del Código Civil y en la formación de una verdadera Escuela de civilistas peruanos. A propósito de la modernización del derecho de obligaciones en Alemania (Schuldrechtsmodernisierung)", Mimeo, Pisa, 2003, p. 5.

36 Sobre el particular Leysser León afirma lo siguiente: «Se trataría, pues, de una "Escuela a la peruana"», que se constata en la "historia de nuestro código civil hecho a pedazos, en una frankensteineana reunión de normas extranjeras por parte de académicos y políticos que se limitaron a hacer "su parte", sin buscar jamás la concordancia con cuanto iban escribiendo los demás redactores: el libro dedicado a las personas, es de influencia italiana; el libro sobre el acto jurídico es seudo francés en su denominación, alemán en su primera norma (con pinceladas inspiradas en el Código Civil de Brasil de 1916) e italiano en su estructura interna; el libro sobre la familia tiene alguna cercanía con la doctrina y legislación española (a las que ninguno de los demás legisladores prestó atención prioritariamente, y era justo que asi fuera), pero los esponsales son regulados conforme a las prescripciones del Código Civil italiano, y se abusa de las llamadas normas «de aplicación progresiva", que bien hariamos en calificar de declaraciones demagógicas (defecto atribuible a la visión más política que jurídica de su redactor); el libro sobre las sucesiones es el más variopinto de todos, y por lo mismo, el de peor estructura interna; el libro de derechos reales 
El resultado, más allá de los problemas internos - es decir, los referidos a la sistemática del código-, recreó un viejo escenario de discusión, esta vez para reubicar nuevamente el andamiaje jurídico en una realidad que le seguía siendo ajena. Más, como se dijo, las líneas básicas del proyecto inicial se mantuvieron en el horizonte, en medio de resistencias internas que, sin perder terreno, aprovecharon algunas de las novedades del nuevo modelo: la idea de los materiales de enseñanza y hasta el método activo sirvieron a este fin. Se gestó así un modelo de vanguardia con anclajes de la tradición legal de mayor reputación, la del derecho civil.

Esta experiencia, en cualquier caso, no tuvo niveles de articulación conocidos con facultades del resto del país. Tampoco se sabe de influencias mediatas. ${ }^{37}$ Sin embargo, la dimensión que el tema de la enseñanza del derecho adquiere en años recientes, como problema, más allá de la PUCP - -el caso de la Universidad Peruana de Ciencias Aplicadas-, corresponde a una agenda marcada por las definiciones del neoliberalismo autoritario de los años noventa.

\section{Enseñanza del derecho y modernización: modelos, cambios y tendencias.}

Las hipótesis de trabajo del presente capítulo son: i) que la falta de eficacia instrumental del modelo tradicional de enseñanza y la dogmática

tiene pasajes de gran originalidad, pero resulta totalmente inconexo y no concordante con el resto de las disposiciones; tenemos una normativa mayoritariamente afrancesada sobre las obligaciones en general y la responsabilidad extracontractual, y un italianizado tratamiento del contrato en general, de los contratos típicos, y de las demás fuentes de las obligaciones; y el triste repertorio puede proseguirm. Ibid., p. 6.

37 Es importante reconocer algunos intentos de cooperación impulsados desde la PUCP con otras universidades del país. Tales esfuerzos, sin embargo, se enfocaron en el desarrollo de actividades académicas puntuales, con la participación de docentes de la PUCP. El caso más notable, por su duración en el tiempo y por la cobertura de sus objetivos, se produjo con la Universidad Nacional de Piura: durante casi tres años (19961999) profesores de la PUCP hicieron docencia compartida con profesores de esa Facultad de Derecho. Los materiales, enfoques y metodología de la enseñanza del derecho fueron los mismos que se aplicaban en la Facultad de Derecho de la PUCP. Los profesores de Lima viajaban una vez a la semana a Piura, ciudad situada a tres horas de distancia por avión. Por razones de presupuesto, el proyecto no pudo sostenerse más allá de tres años, y su continui$\mathrm{dad}$, a través de los profesores de la misma Universidad de Piura, no ha sido posible. 
jurídica — la visión que de ésta se tiene en el caso peruano-se vinculan a la disociación entre teoría y práctica del trabajo académico; ii) que la reacción institucional de las facultades de derecho frente a las reformas institucionales de los noventa, sin ser uniforme, está fuertemente asociada a su influjo; y, iii) que el centralismo y la privatización han permitido la creación de universidades con "fines de lucro", cuya incidencia en el cumplimiento de fines académicos no es del todo nítida.

\subsection{El modelo de enseñanza frente al autoritarismo o la débil eficacia instrumental de la dogmática jurídica}

Varios años después de la experiencia de reforma de los años setenta, la enseñanza en las facultades de derecho del Perú parece haberse mantenido, en líneas generales, ajena y distante de las demandas sociales. ${ }^{38}$ Esta visión, articulada a la idea del derecho como ciencia, se ha visto alimentada en el proceso pedagógico por la separación entre el saber teórico —o dogmática jurídica - y el sentido que el derecho adquiere en su contacto con la vida social: el primero, correspondiente al ámbito de «lo académico»; el segundo, ubicado al margen de este.

La educación legal reprodujo y consolidó esta idea propia de una dogmática más equiparable a la exégesis con ciertos toques de retórica: la enseñanza del derecho equivalía al estudio de las leyes y de los códigos, en función de una teoría y de un método de interpretación propios que buscaban afinar los desniveles del engranaje para que el sistema mantuviera su lógica coherencia. Se propugnaba, así, una dimensión formalista ${ }^{39}$ y cerrada del derecho, que, en el ámbito de la enseñanza, privilegiaba la clase expositiva, con profesores que dictaban y con alumnos que repetían de memoria la información recibida. ${ }^{40}$ Esta idea de la dogmática jurídica

38 Se trata de un cuadro que agrupa, con ligeras variantes, los elementos de la educación legal en América Latina. Felipe González «Evolución y perspectivas de la red universitaria [...]", op. cit., p. 34.

39 Como se ha dicho antes, la baja calidad de la educación legal que reciben los estudiantes de Derecho en muchas universidades del país se vincula al carácter "formalista" de la misma. Puede verse, al respecto, Gabriel Ortiz de Zevallos y Pierina Pollarolo (Editores), Task Forces. Agenda para [...], op. cit., p. 24.

40 Marcial Rubio observa una contradicción - a propósito de la enseñanza del derecho- en el discurso sobre las expectativas de la función creativa del juez. Así, afirma que "[...] el alumno recibe el mensaje del profesor y lo procesa de alguna manera que no 
identifica el derecho con la dimensión de las disposiciones escritas, pero deja de lado la dimensión de la eficacia, le resulta poco relevante el escenario de producción normativa desde posiciones distintas de la legislativa, y no se siente comprometida con la necesidad de desarrollar prácticas argumentativas orientadas a justificar racionalmente los problemas de tipo valorativo que requieran respuestas concretas.

La preocupación de este enfoque del derecho comienza con las definiciones y las estructuras conceptuales para concluir con la comprensión del sistema jurídico como estructura. ${ }^{41}$ Esta visión de lo jurídico opera con un concepto restringido de validez, y lo circunscribe primordialmente al derecho legislado. Le resulta, por ello, distante la pregunta sobre el funcionamiento de la praxis judicial, como mecanismo de validez, pero también de eficacia. Alejada de la necesidad de justificar el razonamiento sino a partir de los presupuestos teóricos del derecho legislado, esta visión de lo jurídico se forja una imagen propia frente al espejo. Y es probable que eso explique que su razonamiento busque replicarse a sí mismo, cada vez que intenta explorar espacios complejos, como el de los casos y las sentencias. Porque es natural, para esta idea, que el derecho venga descrito en leyes o mandatos legislativos, que, en buena cuenta, son la expresión de las normas, sin considerar que éstas últimas, en realidad, se crean por el esfuerzo interpretativo que involucra, precisamente, la dimensión de los casos concretos.

Finalmente aquella idea del derecho deja de lado, también, una parte esencial de la dimensión jurídica que se refleja en la necesidad de dar respuesta racional y fundamentada a los problemas de utipo valorativo que han quedado pendientes de solución en el material autoritativamente ya dado", ${ }^{42}$ pero que adquieren, igualmente, enorme actualidad y relevancia cada vez que se debe hacer frente a un caso concreto.

precisamente es aquella en la cual el mensaje es emitido. Nosotros de un lado le decimos que en el plano de la teoría del derecho enseñamos la labor creativa del juez, pero después la tendencia se vincula al ejercicio de un positivismo casi literal de la ley, particularmente en aquellos aspectos formales del derecho como el Derecho Procesal». Marcial Rubio Correa, "El Poder Judicial que queremos: una perspectiva desde la docencia» en: I Encuentro de Decanos de Facultades de Derecho. Arequipa - Perú, 19 y 20 de septiembre de 1997, Consejo de Coordinación Judicial, 1997, Lima, p. 58.

41 Robert Alexy, Teoría de los derechos fundamentales, Centro de Estudios Políticos y Constitucionales, Madrid, 2002, pp. 31-33.

42 Según Alexy, ésta constituye, en todo caso, la tarea de la dogmática jurídica, entendida como una visión unificante del derecho, precisamente por su carácter práctico. De ahí 
Se trata de un panorama que no pudo ser modificado por la reforma de la enseñanza del derecho de la década de los setenta. Como ya se advirtió, los alcances de ésta solo se remitieron al ámbito interno de la Facultad. Más allá de la PUCP, la enseñanza del derecho se mantuvo asociada a la tradición. Pero incluso en dicha Facultad, el estado de la cuestión que provoca nuevos intentos de reforma de la enseñanza en 1989 y 1998, supone el reconocimiento de que aquella está tomada por una visión dividida e impregnada por el formalismo, que articula el orden del qué y del cómo enseñar. Una perspectiva, en la cual el interés por la crítica del impacto social del derecho, en todas sus dimensiones, tiene un escaso margen de actuación, y el escenario configurado para este efecto es residual.

La escisión entre teoría y práctica se vislumbra en la existencia, de hecho, de ciertos espacios diferenciados e independientes de enseñanza. Un primer caso - visible en la PUCP - es el de las denominadas «clases de prácticas», que estuvieron asociadas a la mayor parte de cursos y que se construyeron, las más de las veces, sobre la base de casos reales que servían como insumo para el debate en clase. En ellas, el método activo de enseñanza cumplió un rol importante, sin llegar a ser hegemónico. Estas clases, salvo excepciones, tuvieron carácter informal y, en buena cuenta, fueron consideradas "complementarias" respecto de la cátedra del curso. Del carácter accesorio de estas clases derivó que su responsabilidad fuera dejada en manos de jefes de prácticas o de estudiantes de últimos ciclos, que hacían las veces de ayudantes. No obstante ello, su popularidad y éxito entre los alumnos fue irrebatible, llegando a convertirse en espacio privilegiado de aprendizaje, en algunos casos más apreciado que el proporcionado por la cátedra oficial del curso. Paradójicamente, este tipo de escenario fue cuestionado por el movimiento reformador y, al mismo tiempo, defendido por quienes estaban en contra - o, por lo menos, no del todo a favor- de la reforma. En esta última línea estaban quienes defendían la cátedra magistral como vehículo para la transmisión de la dogmática.

Un segundo caso que refuerza la disociación entre el saber teórico y la práctica es el que se configura con los cursos denominados "práctica forense", presentes en muchas facultades del país. Son espacios dedicados al trabajo aplicativo, pero, contradictoriamente, atribuidos a un tipo de operador

que, en esa dirección, si la disciplina del derecho ha de cumplir racionalmente su tarea, debe hacerlo, tratando de vincular recíprocamente todas las dimensiones. "Tiene que ser una disciplina integrativa pluridimensional". Ibid, p. 33. 
conectado al oxígeno del formalismo jurídico. En tal sentido, en este tipo de cursos se enseña el cómo desde la perspectiva de lo formal, con modelos que demuestran cómo hacer una demanda, cómo contestarla, cómo redactar una sentencia, cómo preparar un escrito de apelación, cómo y dónde citar las normas legales correctamente, etc., son las partes que sucesivamente conforman la cronología del curso. No existe, en este tipo de cursos, espacio para discutir la determinación de los problemas legales ni para el análisis y formulación de los argumentos jurídicos en el contexto de estrategias de litigación.

El tercer caso está presente en la idea que dio origen al funcionamiento de los consultorios legales. Su carácter extracurricular en la mayor parte de universidades - principalmente públicas - en donde existen, ${ }^{43} \mathrm{com}$ binado con la existencia de los cursos de "práctica forense", configura un modelo de formación que divide y desarticula la idea del derecho. En este tipo de institucionalidad, las potencialidades y destrezas del trabajo legal, como fuente de educación y cambio social, no forman parte de su ideario. Su preocupación, con todo el valor que representa desde el punto de vista de la moral y la solidaridad, está más atento a los casos individuales -en tanto expresión superficial de problemas estructurales que se mantienen ajenos al trabajo del consultorio-,${ }^{44} \mathrm{y}$ no se advierte como una extensión articulada a la metodología de la educación legal ni se recoge como insumo que enriquezca la propia teoría legal. En esta tradición se percibe, más bien, una agenda de tipo "asistencial" para los pobres, de la que no se esperan, necesariamente, resultados hacia «lo académico».

43 Esta actividad es de tipo extracurricular en muchas universidades. En la PUCP, se inserta, por cierto, en un programa curricular más articulado de proyección social, denominado PROSODE (Proyección Social de Derecho). De cualquier forma, la labor específica del consultorio en términos generales, involucra un tipo de práctica asistencial que no está pensada necesariamente como espacio de formación académica.

44 El carácter paternalista y las limitaciones de este tipo de metodologías extracurriculares fue puesto en evidencia por Fernando de Trazegnies hace poco más de treinta años: «En efecto, algunas Escuelas de Derecho han instalado oficinas legales en urbanizaciones para personas de modestos recursos, los alumnos les han dedicado una parte más o menos generosa de su tiempo marginal, los problemas atendidos han sido fundamentalmente aquellos que solo constituyen meras expresiones superficiales de males sociales profundos que permanecen esencialmente ajenos al trabajo del consultorio; todo ello, antes que al cientifico social, recuerda a la señora feudal que sale de su castillo con una elegante canasta bajo el brazo para darle pan a los pobres». Fernando de Trazegnies, «La enseñanza del Derecho como actividad subversivan, op. cit, p. 62. 
Pero el discurso que justifica la escisión entre teoría y práctica en la enseñanza del derecho, será presa fácil del pragmatismo neoliberal que abandera las «reformas" de la década de los noventa. Y es que las reformas gestadas por el régimen fujimorista produjeron una institucionalidad, ajustada a sus requerimientos prácticos, de modo que toda pretensión de justificación resultaba "simbólica», pues la fuerza había sido ya impuesta como fuente privilegiada y exclusiva del poder. Por ello, el escenario institucional y el discurso que lo sustentan, solo se explican desde la perspectiva de una lógica instrumental y pragmática, ${ }^{45}$ es decir, como herramientas orientadas a concentrar el poder del régimen. ${ }^{46} \mathrm{Y}$ el razonamiento que sirve de base para ello supone que el derecho y las leyes sirven a fines, propósitos y políticas identificables de manera independiente de las prácticas o medios. ${ }^{47}$

Se trata de un escenario vertiginoso que demanda respuestas y soluciones eficaces desde el derecho. ${ }^{48}$ En el fondo de este espacio, la enseñanza

\footnotetext{
45 Robert Summers, "Pragmatic instrumentalism in Twentieth Century American Legal Thought - A Synthesis and Critique of Our Dominant General Theory about Law and its User en: Cornell Law Review, No 66, 1981.

46 Sinesio López ha caracterizado al estilo fujimorista como «una combinación explosiva de la improvisación, el autoritarismo burdo y la trampa». Es un estilo en el que las consignas centrales son: «Todo vale; sálvese quien pueda y como pueda; el que pestañea pierde. Su vigencia supone el debilitamiento de los valores y las normas pre-establecidas de la conducta social civilizada así como el desprecio olímpico por las reglas del juego político aceptadas por todos». Silesio López, «Fujimori y la crisis de la Civilización del siglo XX» en: Desde el límite. Perú, reflexiones en el umbral de una nueva época, IDS, Lima, 1992, p. 225.
}

47 Una escasa preocupación por los medios, o bien un pragmatismo «radical», suele formar parte de las políticas que orientan estos regímenes y no es extraño que la personalidad de quienes lideran este tipo de proyectos políticos encarnen esta modalidad de antivalores. Así, por ejemplo, para el Ministro de Economía del régimen, no hubo problema alguno en que el presidente Fujimori ganara las elecciones predicando el "no" ajuste y después buscara articular un equipo de orientación ortodoxa que lo asesorara en sus reuniones con los organismos financieros, para hacer todo lo contrario, pues «si bien esos planteamientos podían ser efectivos para ganar una elección, no lo eran para gobernar el país". Carlos Boloña, Cambio de Rumbo. El programa económico para los 90, Instituto de Economía de Libre Mercado «San Ignacio de Loyola», Lima, 1993, pp. 21-22.

48 Lynne Henderson, "Authoritarianism and the Rule of Laus en: Indiana Law Journal, Vol. 66, 1991, p. 396. Para asegurar su hegemonía, un gobierno dictatorial requiere algo más que el uso de métodos coercitivos. La historia, en múltiples casos, ha demostrado que estos regímenes alternan la utilización de medios «más pacíficos" para asegurar su poder. De 
tradicional del derecho —envuelta en los dilemas «teóricos» de la codificación o de su carácter científico- se resquebraja sensiblemente ante la arremetida de una "nueva" perspectiva, funcionalista, atenta a la exaltación de un mercado imaginario, pero convertido en criterio de racionalidad, afín al tipo de democracia de baja intensidad que derivaba del propio régimen político: una versión del análisis económico del derecho, ${ }^{49}$ que, sin embargo, proyecta un nuevo tipo de dogmática ${ }^{50}$ - esta vez "para llevar" - de profunda carga ideológica, que introduce la eficiencia como el único criterio para medir la justicia de un sistema jurídico. Una perspectiva que cubre con un manto de tecnicismo y aparente neutralidad los factores de poder y desigualdad que están en la base de los conflictos, como si la capacidad de traducir un problema a términos cuantitativos bastara para convertirlo en una cuestión puramente técnica. ${ }^{51}$ En esta perspectiva, sin embargo, el método activo de enseñanza es asumido como vehículo esencial para su desarrollo.

La propia caída del régimen autoritario y el desprestigio de sus reformas, contaminadas por el caudal de la corrupción y el fracaso de sus presupuestos económicos ${ }^{52}$ y políticos, parecen haber debilitado la hegemo-

hecho, en estos gobiernos se busca, por ejemplo, neutralizar políticamente la función judicial en post de que las respuestas de los jueces sirvan de conexión directa entre el nuevo punto de gravedad del sistema político y las tensiones sociales.

49 Paradójicamente, la disciplina se introdujo como curso lectivo a través de la Pontificia Universidad Católica, pero no logró expandirse con la misma fuerza que su discurso. Solo la Universidad de Lima y la Universidad Peruana de Ciencias Aplicadas la replicaron. En todo caso, la perspectiva del análisis económico también ha sido usada como herramienta para el re-enfoque de cursos tales como Responsabilidad Civil, Derecho de los Contratos, Derechos Reales, Introducción al Derecho Civil y Personas.

50 Como advierte Carlos Ramos, con esta perspectiva se introducen un conjunto de instituciones tales como "consumidor razonable», "costos de transacción" o "externalidades", dotadas casi siempre de una perspectiva unidimensional. Ver: Carlos Ramos Nuñez, Historia del Derecho Civil Peruano, T. I.: El orbe jurídico y Manuel Lorenzo de Vidaurre, Pontificia Universidad Católica del Perú, Lima, 2000, p. 35

51 Manuel Atienza, El sentido del derecho, Editorial Ariel, Barcelona, 2001, p.138.

52 De acuerdo al último informe del Instituto Nacional de Estadística e Informática del 2001, que permite verificar el impacto de la política económica de los diez años del gobierno de Fujimori, uno de cada cuatro peruanos (24.4\%) se encuentra en condiciones de "pobreza extrema». "Esta caregoría involucra a las personas cuyos ingresos "son inferiores al costo de la canasta básica de consumo, compatible con una ingesta adecuada de calorías. Se trata, por consiguiente, de una población que no tiene garantizada una alimentación mínimamente adecuada, comprometiendo al mismo tiempo su salud, y en el caso de 
nía, a veces "fundamentalista», del análisis económico del derecho. El nuevo contexto político, pese a todas las dificultades derivadas del proceso de transición -o quizá gracias a él一, ha permitido abrir el espacio del debate académico; prueba de ello es la importancia que ha venido asumiendo, cada vez con mayor intensidad, la reflexión en torno a la democracia constitucional, el enfoque interdisciplinario del derecho desde la filosofía, la historia o la sociología, y, con ello, el posicionamiento de los valores éticos en el derecho y en la comprensión de la política como acto cultural, diluido en los noventa. Se abre, pues, un espacio para la reflexión jurídica crítica atenta a las necesidades históricas y sociales del país que, sin duda, tendrá como un componente importante, pero no único, el factor vinculado a la eficiencia económica. ${ }^{53}$

\subsection{Las instituciones de enseñanza del derecho frente a los cambios en la década de los noventa.}

\subsubsection{Las Facultades de Derecho}

El cuadro que grafica la situación actual de la enseñanza del Derecho en el Perú da cuenta de la existencia de setenta y siete universidades. De ellas, treinta y un son públicas y el resto, privadas. Al mismo tiempo, se cuenta con un total de cuarenta y cinco facultades de derecho, de las cuales dieciocho son públicas y veintisiete, privadas.

\section{Cuadro No $3^{54}$}

Número de alumnos por Facultades de Derecho

\begin{tabular}{|lccccc|}
\hline Universidad & cantidad & Porcentaje & $\begin{array}{c}\text { Facultades de } \\
\text { Derecho }\end{array}$ & cantidad & Porcentaje \\
\hline Pública & 31 & $40.26 \%$ & Pública & 18 & $40 \%$ \\
Privada & 46 & $59.74 \%$ & Privada & 27 & $60 \%$ \\
Toal & 77 & $100 \%$ & Total & 45 & $100 \%$ \\
\hline
\end{tabular}

los niños, su rendimiento escolar y por ende sus ingresos fururos"m Véase: Javier Herrera, La pobreza en el Perú en 2001. Una visión departamental, Instituto Nacional de Estadística e Informática-Institut de Recherche Pour le Développment, Lima, 2002, p. 12.

53 Carlos Ramos Nuñez, op. cit., p. 35. 
Del total de facultades de Derecho, en Lima se concentra la mayor cantidad (doce de cuarenta y cinco). A su vez, y como se verá más adelante, Lima alberga la mayor densidad poblacional: $43 \%$ de un total de 41.192 estudiantes de derecho en el año 2000.

Los regímenes de estudios de todas las universidades suelen tener las mismas pautas para su desarrollo. En todas existe el examen de admisión como regla general. Con algunas excepciones, la mayor parte de ellas tienen estudios generales entre los primeros dos o cuatro semestres. En la mayor parte de facultades los estudios de la carrera propiamente dicha tienen una duración de cuatro años, por lo menos, lo que en conjunto hace un total de 6 años de estudios universitarios, como regla general. ${ }^{55}$ Para egresar se requiere aprobar el número de créditos exigidos por cada facultad y, con ello, se obtiene el Diploma de Bachiller en Derecho, cuyo efecto solo vincula a la posibilidad de seguir estudios de postgrado en las universidades peruanas, pues, para el ejercicio profesional, se requiere la aprobación de un examen de suficiencia profesional, que, en la mayor parte de casos, consiste en el análisis de dos expedientes judiciales concluidos, en un acto público ante a un jurado de profesores.

Ahora bien, frente al proceso de cambios ocurridos en la sociedad peruana durante la década de 1990, las facultades de derecho han reaccionado de diversa manera. Es posible, sin embargo, distinguir cuatro tipos:

i) En algunas facultades se retoman las premisas básicas de la reforma de los años setenta, pero para incidir centralmente en el aspecto metodológico;

ii) En otras facultades, se asume un fuerte compromiso o alianza estratégica con la lógica de los cambios y se ordena el perfil del estudiante en función de ellos;

iii) Existen facultades con una línea de continuidad de los contenidos y de los métodos de enseñanza, o, en el mejor caso, donde se vislumbra una "puesta al día» sobre la base de las premisas ya existentes, evitándose, así, posibles cambios traumáticos;

54 Fuente: Dirección de estadística e Informática de la ANR, fecha 21 de septiembre de 2000 .

55 Existen dos universidades que constituyen la excepción a esta regla: la Pontificia Universidad Católica donde los estudios tienen en la actualidad una duración de seis años y medio, y en la UPC donde el período es más bien de cinco años. Sin embargo, hay que anotar que la PUCP acaba de aprobar el recorte del período de estudios a seis años. 
iv) También están aquellas facultades donde se produce un allanamiento a las circunstancias generadas por la «desregulación» y el carácter lucrativo de la actividad universitaria. En este contexto, el riesgo de la informalidad y la debilidad de controles sobre el proceso académico y sus resultados, es inminente.

Ubicada bajo el marco de la primera reacción, la Facultad de Derecho de la Pontificia Universidad Católica del Perú viene gestando, desde agosto de 1998, un nuevo proceso de reforma de la enseñanza, que apunta a su actualización para hacer frente a los cambios del presente y para prevenir las variaciones del futuro. Se predica la idea de un «sistema integrado de enseñanza», que reemplaza la lógica parcelada del plan de estudios ${ }^{56}$ con un marcado énfasis en el método. En líneas generales, la propuesta se resume en los siguientes términos: «Hay que enseñar primero el sistema, con una formación razonable en los conceptos esenciales y las interconexiones. Luego se aprenderán mejor los detalles, los temas profundos y las excepciones. Así habrá un doble proceso de aprendizaje: primero los fundamentos y después, dicho esquema se enriquecerá con los elementos más complejos [...]. Esto no se refiere solo a los cambios del Derecho interno, sino a la creciente interconexión que nuestro Derecho nacional tiene con las normas de otros países y con las internacionales por los procesos de integración y globalización». ${ }^{57}$

El perfil profesional propuesto es: un abogado que conozca los fundamentos y la sistemática del derecho, la metodología para la identificación y solución de los problemas, la capacidad analítica para «aprender a aprender" y, de ese modo, enfrentar los cambios. Su entrenamiento debe permitirle interactuar con los especialistas de otras disciplinas. Se agrega, además, el espíritu ético de trabajo en todos los ámbitos de su especialidad, conforme con las leyes y la moral cristiana.

En el segundo semestre del año 2000 se nombró en la PUCP una comisión de profesores encargada de consolidar el trabajo desarrollado desde aquella iniciativa. Dicha comisión estableció: ${ }^{58}$ i) la necesidad de

56 Marcial Rubio Correa, Proyecto de Nuevo Sistema de Enseñanza del Derecho en la Pontificia Universidad Católica del Perú, Documento de Trabajo, Lima, 25 de agosto de 1998 , p. 1.

57 Ibid., p. 8.

58 Pontificia Universidad Católica del Perú, Memoria del Decano de la Facultad de Derecho, Abril de 1999 - junio de 2002, pp. 8-9. 
emplear el método activo en todos los cursos obligatorios, con discusión de casos; ii) reducir el número de alumnos matriculados por sección (máximo 50); iii) reformular y unificar los contenidos mínimos de los cursos y elaborar un sílabo común para cada curso; iv) introducir un sistema de evaluación permanente para todos los cursos obligatorios, suprimiéndose, así, el examen parcial, pero manteniéndose el examen final; y, v) elaborar materiales de lectura comunes.

Como parte del resultado global de este proyecto, en la actualidad, una vez cumplidos los dos años de Estudios Generales Letras, la duración de los estudios de la Facultad de Derecho se ha reducido en un semestre (es decir, de nueve a ocho semestres). Se han abierto más horarios por curso (entre cuatro y cinco), lo que guarda relación directa con los requerimientos del método activo y con la demanda de los alumnos matriculados.

Para egresar de la facultad se requiere haber aprobado un total de ciento setenta y nueve créditos de los cuales ciento diez corresponden a los cursos obligatorios: doce, a los denominados Seminarios de Integración; y cincuenta y siete, a los cursos electivos. La condición de egresado evoluciona hacia la de Bachiller (grado académico) con el certificado de aprobación del nivel básico (doce ciclos) del idioma inglés. Para la obtención del grado profesional se requiere, previamente, el cumplimiento de un año de prácticas pre-profesionales. Hasta hace algunos meses, se debía prestar, adicionalmente, en forma obligatoria, por un año, el Servicio Social de Graduandos en Derecho (SECIGRA-Derecho), ${ }^{59}$ en una dependencia pública. Hoy este servicio es facultativo. ${ }^{60}$

El graduando tendrá la posibilidad de obtener el grado de abogado, mediante la sustentación pública, ante un jurado de profesores, de una tesis (trabajo de investigación), de una memoria crítica que dé cuenta de algún problema jurídico relevante identificado durante el ejercicio laboral (tres años como mínimo), o de dos expedientes judiciales concluidos.

El plan de estudios vigente de la Facultad de Derecho plantea, en términos temáticos, una tendencia que viene de la reforma de 1970. Los cursos de especialidad representan un universo amplio de posibilidades que, sin embargo, se delimitan por las áreas tradicionales del derecho: derecho administrativo, civil, constitucional, internacional, laboral, mer-

59 El Servicio Civil de Graduandos en Derecho, SECIGRA-Derecho, fue creado por Decreto Ley No 26113 el 24 de diciembre de 1992.

60 Mediante Ley No 27687, se eliminó la obligatoriedad del SECIGRA-Derecho. 
cantil, penal, procesal, tributario. La novedad más notoria está dada por el énfasis en los seminarios de integración. Se trata de cursos problema, articulados por casos reales; de este modo, un tópico determinado es materia de análisis desde diversas perspectivas jurídicas.

En el segundo caso de las reacciones reseñadas, se identifica con claridad a la Universidad Peruana de Ciencias Aplicadas, creada en el marco del Decreto Legislativo No 882 (Ley de Promoción de la Inversión en la Educación), es decir, como persona jurídica con fines de lucro. En este caso, se trata de una Facultad de Derecho orientada por los principios que se promueven desde el ideario del régimen de los noventa, que vislumbran una sociedad articulada por propietarios y consumidores a través de la libre competencia y el mercado sin restricciones. ${ }^{61}$

En esa dirección el perfil profesional que gobierna los estudios de derecho en esta facultad es, en buena cuenta, el que goza de mayor claridad, por su definición, por sus objetivos, por el tipo de público al que va dirigida la oferta educativa y por los medios que utiliza para ello: abogados líderes en la asesoría de negocios y empresas, predispuestos a la conciliación y a la negociación antes que al litigio. Su preparación les permitirá manejar el razonamiento jurídico con capacidad de interacción con profesionales de otras disciplinas, con destrezas para el diseño; operación de transacciones, y con conocimientos para interpretar, redactar informes y documentos jurídicos de orden legal, contractual y jurisdiccional..$^{62}$

Se trata de un perfil de abogado que privilegia la asesoría de empresas y que restringe su acción a un tipo de mercado laboral muy preciso y elitista, ${ }^{63}$ en el que el Poder Judicial no aparece como espacio laboral, ni como ámbito de referencia para la solución de conflictos.

61 Estos principios están en la base del Programa de Reforma de la Economía en el Perú, que se inició con el autogolpe de Estado de Alberto Fujimori. Como bien advierte el Ministro de Economía de aquel entonces y líder de la reforma en cuestión. Carlos Boloña Behr, Cambio de Rumbo. El programa económico para los 90, Instituto de Economía de Libre Mercado-SIL, Lima, 1993, pp. 41- 45.

62 Información extraída de la página web

http://www.upc.edu.pe/carreras/derecho/hojas/carrera. htm el 30 de noviembre de 2002.

63 En un reciente estudio empírico sobre el Poder Judicial, realizado bajo el auspicio del Banco Mundial, se observó que, quienes más acuden a estas formas no judiciales de solución de conflictos son las empresas. Véase: Gorki Gonzales Mantilla (Coordinador), Jean Carlo Serván, Luciano López y Hernando Burgos, «El sistema judicial en el Perú: un 
Precisamente, el plan de estudios confirma esta percepción. Organizado en función de los principios antes indicados, se levanta un modelo donde las materias de Derecho Constitucional y Derechos Humanos están prácticamente ausentes (hay un curso de Gobernabilidad) y la visión tradicional del derecho está en retirada, pues los cursos que la asumían (Acto Jurídico, Obligaciones, Teoría General del Proceso, entre otros) simplemente no figuran como tales. Lo mismo ocurre con materias que incorporan el enfoque moral, social y cultural en el análisis jurídico (Filosofía del Derecho, Sociología del Derecho y/o Antropología del Derecho). La lógica del plan de estudios se expresa, a través de cursos que privilegian un enfoque económico, patrimonial y empresarial. La base del plan parece estar articulada en función de materias sobre destreza le$\mathrm{gal}^{64}$ y racionalidad económica, como plataforma para el estudio de Contratos, Responsabilidad Civil, Delitos Económicos, Regulación del Mercado de Valores, Finanzas para abogados, Contabilidad para abogados, Finanzas Corporativas, entre otros.

Por último, dos rasgos terminan de definir el perfil de esta Facultad de Derecho: no presenta un ciclo previo dedicado al estudio de las humanidades. En consonancia con lo anterior — pero, además, con la idea de lograr un posicionamiento eficaz y célere en el mercado-, la duración de los estudios ha sido fijada en diez semestres, un año menos que en el resto de las facultades del país.

En la tercera de las reacciones advertidas, se ubica la mayor parte de universidades públicas y privadas creadas antes de la dación del Decreto Legislativo No 882, Ley de Promoción de la Inversión en la Educación. ${ }^{65}$

enfoque analítico a partir de sus usos y de sus usuariosm. Informe final. Lima, 2002. Este informe se halla en edición final para su próxima publicación.

64 En la óptica de desarrollar las destrezas legales como método de trabajo jurídico, todavía hay quienes afirman la posibilidad de que el Derecho pueda ser definido como una herramienta "desideologizada", útil, en tal sentido, para resolver los retos y problemas que la profesión impone a los abogados en forma cotidiana. Desde esta percepción, el factor solidario no corresponde al paradigma del Derecho que se auspicia, el mismo que mantiene un conjunto de valores alternativos, tales como el servicio eficiente y competitivo a los clientes. Puede verse, al respecto, Shoschana Zusman, «Nuevas tendencias en la enseñanza del Derecho: la destreza legal", en: Derecho PUC, N 52, Fondo Editorial PUCP, Lima, 1998, pp. 934-935.

$65 \mathrm{La}$ información requerida para este punto ha sido obtenida de las páginas web de las siguientes universidades: 
En algunas de ellas, el perfil profesional combina aspiraciones de tipo ético y moral con declaraciones sociales, ${ }^{66}$ salvo excepciones, como la Universidad de Lima, donde se privilegia un enfoque de los estudios más orientado hacia el ámbito empresarial. Es curioso el caso de la Universidad Nacional Mayor de San Marcos -la más antigua del Perú y de América Latina - , pues vincula el perfil profesional con el carácter «científico" del derecho; así, se afirma que el abogado de esa casa de estudios se forma en la "ciencia jurídica» para desempeñarse en cualquier espacio del quehacer legal. ${ }^{67}$

Los planes de estudios de estas facultades mantienen, en líneas generales, un esquema de cursos de humanidades previos, que suele oscilar entre

-Universidad de Lima (bttp://www.menta.ulima.edu.pe/u.../ BE9777A7314D056E05256A9/ D005AD94C?OpenDocumen) - 30.11.2002;

-Universidad Particular San Martín de Porres (http://wnuw.usmp.edu.pe/carreras/derecho) - 30.11.2002;

-,Universidad Católica Santa María (http://www.ucsm.edu.pelpagprg62.htm) 29.11.2002;

-Universidad Femenina del Sagrado Corazón (http://www.unife.edu.pelfderecho) 29.11.2002;

-Universidad Privada de Tacna (http://www.utp.edu.pelfade) - 28.11.2002;

-Universidad de Piura (bttp://www.derecho.udep.edu.pe) - 29.11.2002;

-Universidad César Vallejo (http://www.ucv.edu.pelescuelas/derecho) - 29.11.2002;

-Universidad Nacional Mayor de San Marcos (http://www.unmsm.edu.pelderecho) 30.11.2002;

-Universidad Nacional Federico Villarreal ( $h t t p: / / w w w$ unfubib.edu.pelfacultades/fdccpp. htm1) -30.11.2002;

-Universidad Nacional José Faustino Sánchez Carrión (http://www.concytec.gob.pel unsaca/paginas/infoacalinfo_pag/facultades/fac...(derecho. htm1) - 30.11.2002;

-Universidad Nacional San Cristóbal de Huamanga (http://www.universia.edu.pelunsch/ EFP derecho. htm) - 29.11.2002;

- Universidad Nacional San Antonio de Abad del Cusco (http://www.unsaac.edu.pel web/ wacademicalfacultades/derecho) - 28.11.2002; y,

- Universidad Nacional San Agustín (bttp://www.unsa.edu.pelesc/derecho) - 28.11.2002.

66 Por ejemplo, en el caso de la Facultad de Derecho de la Universidad Particular San Martín de Porres, el perfil profesional es una declaración de principios. Se dice que sus profesionales tienen "[...] un amplio sentido de responsabilidad en su compromiso con los más necesitados, capacidad de autocontrol, equilibrio emocional [...] así como un alto sentido de compromiso con la verdad». Información extraída el 30 de noviembre de 2002 de la página web http://wwwusmp.edu.pelcarreras/derecho.

67 Información extraída el 30 de noviembre de 2002 de la página web bttp:// unuw.unmsm.edu.pel derecho. 
los dos o tres semestres iniciales con carácter obligatorio, con un programa de facultad que también combina los cursos obligatorios y los cursos electivos. Los cursos obligatorios obedecen a un esquema similar, ajustado - en la mayor parte de casos- al orden de los Códigos. El número y la variedad de cursos electivos que se brindan, guardan relación directa con el presupuesto - para contratar más docentes y contar con recursos bibliográficos- del que disponen las universidades, lo que sitúa en desventaja a las públicas ${ }^{68}$ respecto de las privadas, con la enorme importancia de encontrar a los profesores especialistas que asuman la respectiva carga lectiva. Esto último vale tanto para las universidades públicas como para algunas privadas, principalmente de provincias.

En todas estas facultades, la duración de los estudios es de doce semestres (seis años). Los requisitos para egresar son prácticamente los mismos en cada una de ellas, salvo ligeras diferencias en el valor de los créditos asignados a determinados cursos. ${ }^{69}$ El bachillerato, es decir, el grado académico que se obtiene al haber egresado de la facultad, consiste en un simple trámite administrativo, luego de cumplido el paso anterior. Para obtener el título profesional, el estudiante tiene igualmente dos posibilidades: la sustentación, ante un jurado de profesores, de una tesis o de dos expedientes judiciales concluidos.

Como expresión de la última de las reacciones identificadas, se ubican la mayor parte de facultades ${ }^{70}$ creadas bajo el marco del Decreto Legislativo $\mathrm{N}^{\circ} 882$, Ley de Promoción de la Inversión en la Educación, de 8 de noviembre de 1996. Su actuación, por lo tanto, no supera, en ningún caso, los siete años desde su creación. Estas facultades obedecen a la lógica de cualquier entidad con fines de lucro. Son básicamente negocios, y es

68 De esta manera, mientras la Facultad de Derecho de la Universidad Nacional San Antonio Abad del Cuzco tiene 23 cursos electivos, la Universidad de Lima (privada) tiene 58 cursos electivos.

69 A modo de ejemplo, el número de créditos exigidos para egresar de la Universidad San Martín de Porres es de 220; el de la Universidad de Lima, 261; y el de la Universidad César Vallejo de Trujillo, 250.

70 Universidad Nacional de La Amazonía Peruana, Universidad Nacional Jorge Basadre Grohmann, Universidad Nacional de Ucayali, Universidad Nacional de Tumbes ( $h t t p: / /$ www.untumbes.edu.pe/Derecho.htm 1), Universidad Particular Alas Peruanas, Universidad Particular San Pablo, Universidad Privada «San Juan Bautista», Universidad Tecnológica del Perú (bttp://www. utp.edu.pelfacultaldere), Universidad Particular Santo Toribio de Mogrovejo (http://www.usat.edu.pe/carreras/drecho.htm), Universidad Privada San Pedro (http://www.upsp.edu.pelescuelas/derecho), y Universidad Particular Señor de Sipán. 
posible que esta orientación incida negativamente sobre la calidad de la enseñanza. Algunas características de estas facultades son semejantes formalmente hablando - a las previstas en el caso anterior: la duración de los estudios y las exigencias para obtener los grados y títulos. Las diferencias están dadas por la falta de claridad en el perfil profesional ${ }^{71}$ y por la presencia de vacíos en los planes de estudios: no se observa la existencia de cursos electivos. Tampoco se aprecia preocupación alguna sobre el método de enseñanza. Un punto álgido es el relativo a quiénes ejercen la docencia en estas universidades, pues, en realidad no existe información sobre este eje fundamental de la enseñanza del derecho. La educación legal en estas facultades, con muchas más limitaciones, parece discurrir por el mismo cauce de la educación tradicional, forjada prácticamente en la transmisión de información y en la repetición de códigos y comentarios exegéticos como principales fuentes e instrumentos de formación.

\subsubsection{Los estudios de postgrado}

Es desde la segunda mitad de los ochenta y por efecto de la entrada en vigencia de la nueva ley universitaria, que se produce un impulso a los estudios de postgrado en el país. ${ }^{72}$ En particular, en la ciudad de Lima, se inician los programas de maestrías y, progresivamente, se irán articulando los cursos de doctorado. De acuerdo a las reglas previstas en la ley universitaria, tanto la maestría como el doctorado tendrán una duración de dos años, siendo condición para el ingreso a este la aprobación de aquella.

71 Por ejemplo, el perfil profesional de la Facultad de Derecho de la Universidad Tecnológica del Perú (ubicada en la ciudad de Lima), se expresa a través de una declaración de valores sin referencia alguna a la idea de competencias o destrezas propias del trabajo jurídico. Más aún, se afirma que el profesional egresado de sus aulas estará en aptitud de desempeñarse en un universo de ocupaciones amplísimo: jueces, árbitros, fiscales, políticos, diplomáticos, periodistas, consultores internacionales, etc. Información extraída el 29 de noviembre de 2002 de la página web http://www.utp.edu.pelfacultadldere.

Por su parte, llama la atención la "concreción" del perfil profesional de la Facultad de Derecho de la Universidad San Juan Bautista, también de la ciudad de Lima: «El egresado está capacitado para enfrentar situaciones legales en las que tenga que interpretar y aplicar la ley, sin perder de vista uno de sus más preciados fines: la justicia".

72 La entrada en vigencia de la Ley No 23733, Ley Universitaria, en el año de 1984, y la aprobación de los estatutos internos de cada universidad, son consecuencia del proceso político que se vivió en el país luego de la dictadura de los años setenta, que concluyera con la dación de la Constitución Política de 1979. 
Para el año 2000, en el país, según información de la Asamblea Nacional de Rectores, ${ }^{73}$ existían trescientas treinta y dos maestrías y treinta y tres doctorados. Las cifras estimadas de ese año señalan que, en las universidades públicas, el número de maestrías era de doscientos doce y el de doctorados, de diecisiete. Las universidades privadas contaban, por su parte, con ciento veinte maestrías y con dieciséis doctorados.

En la actualidad, la mayor parte de universidades con facultades de derecho, tienen por lo menos una maestría. ${ }^{74}$ Los doctorados se han situado principalmente en Lima y son cuatro. ${ }^{75}$ En general, las maestrías se han desarrollado en torno a ejes temáticos tradicionales: derecho civil, penal, laboral, constitucional o tributario, aunque, desde fines de 1990, empezaron a surgir maestrías más especializadas: derecho empresarial, política jurisdiccional, y derecho de la competencia y de la propiedad intelectual, principalmente. El cuadro siguiente refleja el número de maestrías y doctorados en derecho: ${ }^{76}$

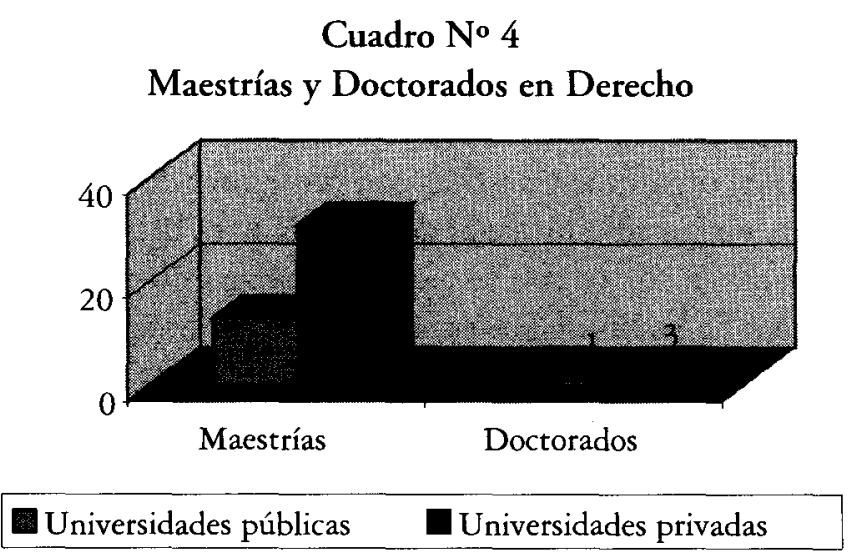

73 Asamblea Nacional de Rectores. Dirección de Estadística e Informática. Información al 21 de setiembre de 2000.

74 La Pontificia Universidad Católica del Perú tiene ocho maestrías: Derecho Civil, Derecho Constitucional, Derecho de la Empresa, Derecho de la Propiedad Intelectual y de la Competencia, Derecho en Política Jurisdiccional, Derecho Internacional Económico y Derecho Penal.

75 Los doctorados en Lima se llevan a cabo en la Pontificia Universidad Católica del Perú, en la Universidad Inca Garcilaso de La Vega, en la Universidad Nacional Mayor de San Marcos y en la Universidad San Martín de Porres.

76 Esta información ha sido obtenida de los sitios de internet de cada una de las universidades públicas y privadas del país. 
Las maestrías en Derecho surgieron con el ímpetu de convertirse en espacios de investigación, privilegiando, entre sus filas, a quienes provenían del ejercicio docente. No obstante, con el tiempo, este perfil fue debilitándose por la emergencia de sectores profesionales que buscaban espacios de actualización y de desarrollo de destrezas para su desempeño en las diversas áreas del trabajo jurídico operativo. La visión estrictamente académica de las primeras maestrías empezó a ceder a la demanda del mercado y surgieron, como se dijo, maestrías más especializadas; o, de otro lado, las maestrías originalmente concebidas empezaron a abrir sus estructuras, buscando lograr un equilibrio entre la demanda urgente y el desarrollo de sus propios proyectos académicos.

Esta, en todo caso, no es la historia de todas las maestrías. Las que aparecen en las ciudades del interior del país - y muchas de la capitaltendrán severas limitaciones desde sus inicios, tanto para concebir los planes curriculares cuanto para estructurar metodologías de trabajo académico. Y la parte más importante de esas dificultades es que, probablemente, en la mayoría de estas universidades el número de profesores de derecho con postgrado era muy bajo y, en algunos casos, inexistente. Hasta el día de hoy, la estrategia - para el caso de las universidades de provinciassuele consistir en organizar maestrías con profesores de la capital, quienes, muchas veces, viajan solo los fines de semana para brindar las clases respectivas.

En el núcleo de las limitaciones con las que nacen estas maestrías, está igualmente la precariedad de las bibliotecas jurídicas. Sin embargo, la propia dinámica adquirida por la orientación práctica de estos estudios, en el caso de muchas de las maestrías existentes, ha permitido "sortear" esta dificultad con su omisión por parte de las universidades, con la aquiescencia del órgano respectivo de la Asamblea Nacional de Rectores y con la despreocupación de los propios estudiantes. En realidad, es posible detectar que muchos de estos postgrados se han convertido en espacios de actualización profesional, sin proyección en el área de la investigación. Y, en todo caso, surge de ellos una expectativa de tipo instrumental, es decir, como forma de legitimación formal en el ámbito laboral. Todo este panorama se vislumbra, con suma crudeza, cuando se comprueba el escaso número de egresados que concluyen la tesis y que logran optar al grado de Magíster en Derecho.

Parece ser que el modelo de maestría académica deberá ser replanteado, propiciándose otras opciones, de modo que resulten mecanismos de ca- 
pacitación funcionales a la demanda del mercado profesional, pero buscándose, de otro lado, la apertura del espacio adecuado para el trabajo académico y para el desarrollo de la investigación. En esta óptica se ubican los esfuerzos institucionales por generar alianzas estratégicas con universidades del extranjero, creando sistemas de doble acreditación y, eventualmente, estadías de investigación, es decir, ampliando el abanico de posibilidades. Del mismo modo, es una alternativa que se empieza a explorar la que proporciona la educación a distancia, mediante el empleo de los medios electrónicos de transmisión de información. ${ }^{77}$

En el caso de los doctorados, la realidad no muestra una evolución importante, debido a su escasa demanda, ya sea porque no existen candidatos hábiles —es decir, con el grado de magíster-, o bien porque su objetivo académico central resulta de poco atractivo para un mercado donde los potenciales interesados - los docentes - no dedican a esta actividad sino un tiempo marginal. Por todo ello, en realidad, no se observa un impacto importante, que provenga de este tipo de postgrado y que incida positivamente en el desarrollo de las facultades de derecho.

\subsection{Estudiantes y docentes de Derecho: entre la desregulación y el centralismo}

Las reformas políticas gestadas en el marco del desmoronamiento institucional de fines de los ochenta implicaron una "[...] transformación radical del Estado que ha perdido su lugar hegemónico en la sociedad, ha visto recortadas sus funciones y reducido su tamaño; pero al mismo tiempo se ha vuelto más rígido y excluyente como forma de dominación social. Las clases medias y populares incrementaron su empobrecimiento y la informalidad se intensificó [...]. El programa de estabilización y el ajuste estructural así como la violencia política han minado el proceso de democratización así como la participación política de la ciudadanía, lo que se vio agravado con el autogolpe del 5 de abril de $1992 »{ }^{78}$

77 En la Pontificia Universidad Católica del Perú se vienen promoviendo, a través de la modalidad a distancia y desde hace algún tiempo, diplomas y cursos de especialización en Derecho.

78 Sinesio López, «Estado, régimen político e institucionalidad en el Perú (19501994)", en: El Perú frente al siglo XXI, op. cit, p. 568. 
La universidad peruana, en este último período, fue centro de atención del gobierno fujimorista. La modernización autoritaria de dicho régimen se expande con una doble lógica: intervención en algunas universidades públicas en pos de enfrentar la violencia política, instituyendo autoridades para que impusieran el "nuevo orden", pero, a la vez, instauraran un régimen legal (Ley de Promoción de la Inversión en la Educación), ${ }^{79}$ que, en la línea imaginaria de la "desregulación", creó una de universidad, privada y con fines de lucro. Y, de acuerdo a su estatuto legal se manifestó una empresa, dependiente ya no de la «autonomía» cifrada en la comunidad que la integra-, sino de sus propietarios, ${ }^{80}$ en un esquema abierto al mercado y a los grupos de interés económico. ${ }^{81}$

De este último extremo, se explica la aparición de un número significativo de universidades privadas, todas ellas —o casi todas - con Facultades de Derecho. El gráfico No 5 refleja la situación derivada de este proceso:

\section{Cuadro No 5}

Impacto del Decreto Legislativo No 882, Ley de Promoción de la inversión en la Educación (en vigencia desde el 10 de noviembre de 1996), en la creación de universidades con facultades de Derecho-Perú

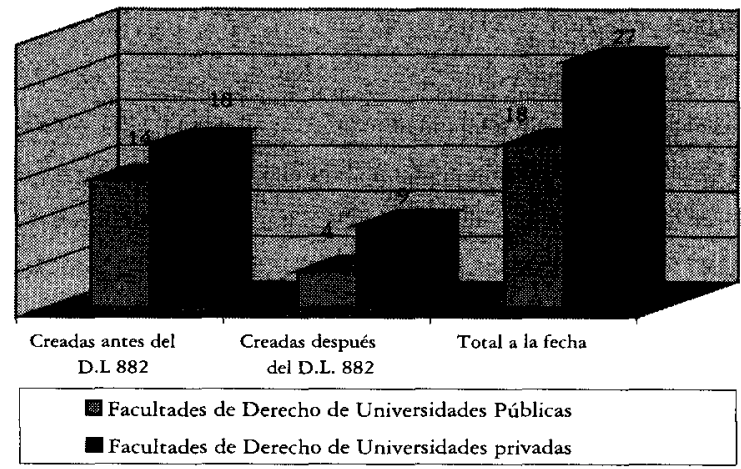

Fuente: Elaboración propia a partir del Boletín «Perú: Estadísticas Universitarias" (Año 9, $\mathrm{N}^{\circ} 10$, 1998), expedido por la Secretaría Ejecutiva de la comisión de coordinación Interuniversitaria de la Asamblea Nacional de Rectores.

79 Se trata de la Ley de Promoción de la Inversión en la Educación (Decreto Legislativo No 882, publicado en el diario oficial «El Peruano» el 9 de noviembre de 1996). El artículo $2^{\circ}$ de esta ley dispone: «Toda persona natural o jurídica tiene el derecho a la libre iniciativa privada, para realizar actividades en la educación. Este derecho comprende los de fundar, promover, conducir y gestionar Instituciones Educativas Particulares, con o sin finalidad lucrativa».

80 René Ortiz Caballero, op. cit., pp. 89-91

81 Por lo demás, no deja llamar la atención la subsistencia de la tasa de analfabetismo de 


\subsubsection{La demografia de los estudiantes de derecho}

Luego de la puesta en vigencia del Decreto Legislativo No 882, el número de Facultades de Derecho en las universidades privadas se incrementó en un $50 \%$ (de dieciocho a veintisiete). Más aún, el número de facultades de Derecho de las universidades privadas sobrepasó ampliamente el de las universidades públicas, que solo creció en cuatro facultades: de catorce a dieciocho. Como ya se anticipó, el número actual, incluyendo públicas y privadas, no es menor de cuarenta y cinco facultades de derecho en todo el país. La misma explicación rige para el incremento que experimenta la población de estudiantes de las universidades privadas a partir de la puesta en vigencia de dicha norma. Así, de 162,410 alumnos matriculados en 1996, se llegó a 171,289 en el año 2000; es decir, se produjo un incremento de más 8.000 estudiantes en solo cuatro años. ${ }^{82}$

De otro lado, la masificación - sin un crecimiento proporcional de los servicios y la infraestructura - pondría en cuestión la calidad de la formación académica en general, con el agravante del impacto que esto representa en las careras de derecho, debido a la existencia de ciertos espacios laborales de carácter cautivo, es decir, solo para abogados. Una de las instituciones donde este aspecto puede tener una repercusión notable es el ejercicio de la función jurisdiccional. No resulta extraño que, años más tarde, el Grupo Apoyo, en un informe de enero de 2000, "descubra" como uno de los factores que incide negativamente en la calidad profesional de los jueces, es la baja calidad de la educación legal que reciben los estudiantes de Derecho en muchas universidades del país. ${ }^{83}$ El remedio, entonces, sería peor que la enfermedad.

Las tendencias en el crecimiento de la población universitaria guardan una relación precisa con los cambios operados en el país. El centralismo en sus múltiples manifestaciones y el impacto de las políticas públicas orientadas a crear válvulas de escape a la presión social —como el Decreto

personas mayores de quince años durante los años 97,98 y 99 , siempre por encima del $12 \%$ y con un ligero quiebre (11.7\%) en el año 2000. Instituto Nacional de Estadística e Informática. Encuesta Nacional de Hogares 1997-2001, INEI, Lima, 2002.

82 Información obtenida de las siguientes páginas web http://www.universia.edu.pel contenidos/universi/estadisticas/estadisticas_nuevas/matriculados.htm y http://www.inei.gob.pel perucifras.

83 Gabriel Ortiz de Zevallos y Pierina Pollarolo (Editores), Task Forces. Agenda para [...], op. cit., p. 24 
Legislativo No 882 - , se expresan, de una u otra forma, a través de este contexto. El mapa poblacional de alumnos y profesores de derecho se explica, en buena medida, al interior de los límites de este marco de referencia.

\section{Cuadro No 6}

Número de alumnos matriculados

\begin{tabular}{|lcl|lll|}
\hline & \multicolumn{3}{c|}{ Facultades de Derecho $^{\mathbf{8 5}}$} \\
\hline Públicas & 255,276 & $59.84 \%$ & Públicas & 11,322 & $27.49 \%$ \\
Privadas & 171,289 & $40.16 \%$ & Privadas & 29,870 & $72.51 \%$ \\
Total & $\mathbf{4 2 6 , 5 6 3}$ & $\mathbf{1 0 0} \%$ & Total & $\mathbf{4 1 , 1 9 2}$ & $100 \%$ \\
\hline
\end{tabular}

En efecto, como se ha señalado anteriormente (Cuadro $\mathrm{N}^{\circ} 2$ ), la población de los estudiantes de derecho ha experimentado un incremento notable. De 3.391 alumnos matriculados en 1960, se multiplica por diez para el año de 1986, es decir, a 35.503 alumnos matriculados. En cifras aproximadas para el año 2000 , el número de estudiantes de derecho habría ascendido a 41.192 y habría representado el 9,66 \% del total de universitarios matriculados (que asciende a la cifra de 426.563). Si se hiciera la comparación distinguiendo facultades de derecho de universidades públicas y privadas respecto de la cifra global de universitarios matriculados, tendríamos que el 2,66\% (11.322) correspondería a las universidades públicas, en tanto que el 7,02\% (29.870), a las privadas. Todo lo anterior se corrobora cuando, de acuerdo con los datos estimados por la Asamblea Nacional de Rectores para el año 2000, Derecho es la segunda carrera más poblada del país, después de la de Educación.

Un dato significativo es que, aproximadamente, siete de cada diez estudiantes de Derecho corresponden a las universidades privadas. Otra información importante es el número total de postulantes. Para el año 2000 se tuvieron, en total, 36.296 postulantes a Derecho (23.659 a las univer-

84 Fuente: Instituto Nacional de Estadística www.inei.gob.pe/perucifras: Evolución de la Matrícula en Educación Superior - Universidades Públicas y Universidades Privadas, 1990-2000.

85 Asamblea Nacional de Rectores, Dirección de Estadística e Informática, Resumen Estadístico 2001, ANR, Lima, 2002. 
sidades públicas, y 12.637, a las privadas), lo que representa el 9,5\% del universo de postulantes a la universidad peruana (cuyo total fue de 381.447). Téngase presente que, según la información consignada en el Resumen Estadístico 2001 de la Asamblea Nacional de Rectores, ${ }^{86}$ existe un total de ciento treinta y dos carreras universitarias.

\section{Cuadro No 7}

Postulantes a las facultades de Derecho-Perú (2000)

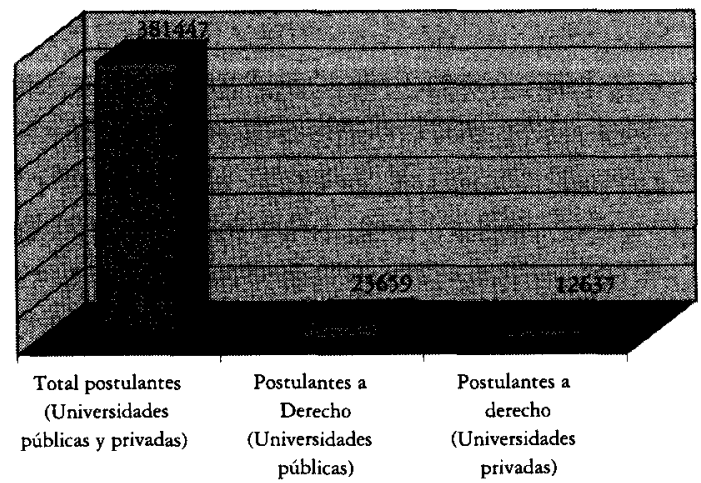

Fuente: Instituto Nacional de estadística e informática.

Evolución de la Matrícula en Educación Superior - Universidades Públicas y Privadas / 1990-2000.

Pero lo que llama la atención es la relación existente entre el número de postulantes a Derecho y el número de ingresantes a las respectivas facultades de las universidades públicas y privadas en el año 2000. Así, mientras en las públicas, de 23.659 postulantes, ingresaron 1,914; en las privadas, de 12.637, ingresaron 6,589. Entonces, mientras uno de cada doce postulantes ingresa a las facultades de derecho de las universidades públicas; en las privadas, de cada dos postulantes ingresa uno.

En otras palabras, un número mayor de vacantes acompañado de un cuadro menos exigente - o simplemente una variedad de oportunidades - a la hora del examen de ingreso, podría explicar el mayor número de postulantes a las universidades privadas, de estrategias de mercado para lograr un mayor número de matriculados. No hay que descartar tampo-

86 Dirección de Estadística e Informática, Resumen Estadístico 2001, ANR, Lima, 2002. 
co la existencia de un porcentaje importante de postulantes sin preparación y sin recursos económicos para "nivelar» sus conocimientos en función de las exigencias de los exámenes de admisión de las universidades públicas. En todo caso, resulta ilustrativa la información del Instituto Apoyo, según la cual entre las facultades privadas con el mayor número de alumnos inscriptos, se encuentran algunas cuya imagen no es bien percibida por a la opinión pública. ${ }^{87}$

La tendencia relativa al sexo de los estudiantes es un dato que no debe pasar desapercibido. Así, el número de postulantes a la Universidad Nacional Mayor de San Marcos en el año 2000 fue de 3,574 mujeres y de 2,941 hombres; en la Universidad Nacional de Trujillo, setecientos cincuenta y seis mujeres y seiscientos treinta y nueve hombres; en la Universidad Nacional San Luis Gonzaga de Ica, ochocientos treinta y cinco mujeres y seiscientos cuarenta y tres varones; en la Pontificia Universidad Católica del Perú, 1.055 mujeres y setecientos dieciocho varones; en la Universidad San Martín de Porres, 2.135 mujeres y 1.833 hombres; en la Universidad de Lima, doscientos cuarenta y cinco mujeres y cinto ochenta y tres varones; y en la Universidad Peruana de Ciencias Aplicadas, setenta y nueve mujeres y sesenta y siete hombres ${ }^{88} \mathrm{El}$ siguiente gráfico traduce la relación entre postulantes varones y mujeres, al año 2000, en veintiocho de las cuarenta y cinco facultades de derecho del país. ${ }^{89}$

87 La Universidad San Martín de Porres tuvo el último lugar en el nivel socio-económico A, y el penúltimo lugar en los niveles socio-económicos $\mathrm{B}$ y C. Postularon, a dicha universidad, 3.968 e ingresaron 906. Llama la atención el caso de la Universidad Inca Garcilaso de la Vega, la cual no aparece entre las respuestas a la mejor Facultad para estudiar Derecho sino hasta octubre del 2002, solo en el Nivel Socio Económico C y en el último lugar. Esta Facultad de Derecho tuvo, en el año 2000, 1.455 postulantes y 1.342 ingresantes.

88 Esta información ha sido obtenida de los informes o reportes estadísticos remitidos anualmente por cada Universidad a la Asamblea Nacional de Rectores. También fue necesario recurrir a la información proveída directamente por algunas de las Facultades de Derecho.

89 Los porcentajes obtenidos derivan de la información de veintiocho universidades del país. Entre las universidades públicas están la Mayor de San Marcos, la de Trujillo, la San Luis Gonzaga de Ica, la de San Cristóbal de Huamanga de Ayacucho, la de La Amazonía Peruana, la de Piura, la Nacional de Cajamarca, la Universidad Pedro Ruiz Gallo de Lambayeque, la Hermilio Valdizán de Huánuco, la Jorge Basadre Grohmann de Tacna y la de Ucayali. Entre las universidades privadas encontramos a la Pontificia Católica del Perú, a la Católica de Santa María de Arequipa, a la de Lima, a la de San Martín de Porres, a la 


\section{Cuadro $\mathrm{N}^{\circ} 8$}

Distribución de postulantes a las facultades de Derecho de las Universidades, según su sexo-Perú (2000)

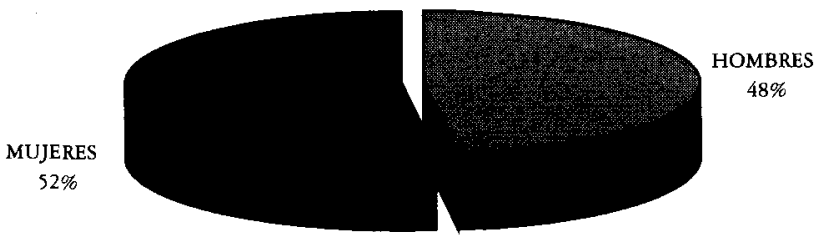

Estas cifras podrían constituir indicadores simplemente demográficos, pero también dan cuenta del proceso de incorporación de la mujer al mundo profesional. Más aún, sugieren una tendencia relativa a la competencia de géneros en espacios tradicionalmente masculinos. Sin embargo, se trata de una información que debe contrastarse con el escenario profesional propiamente dicho. En efecto, razones derivadas de la actual segmentación del mercado de trabajo pueden incidir en el predominio cuantitativo y de posicionamiento de los varones en los cargos más importantes; $y$, de otro lado, también es probable que sea mayor el número de varones que concluye sus estudios de derecho y desarrolla su carrera, en vista del cambio de prioridades que el embarazo y la familia pueden significar en la mujer. ${ }^{90}$

Femenina del Sagrado Corazón, a la Inca Garcilaso de la Vega, a la de Piura, a la Andina Cáceres Velásquez de Puno, a la Peruana Los Andes de Junín, a la Universidad de Huánuco, a la Tecnológica de los Andes de Abancay, a la de Chiclayo, a la Universidad San Pedro de Chimbote, a la de Moquegua, a la de Iquitos, a la Peruana de Ciencias Aplicadas y a la Alas Peruanas.

90 El $44 \%$ de la Población Económicamente Activa (PEA) del país es femenina. La participación creciente de la mujer en el mundo laboral es una realidad. No obstante, la discriminación entre varón y mujer sigue prevaleciendo. Ello explica el que la mujer se vea constreñida a realizar labores atípicas, poco calificadas y con remuneraciones diferenciales. Así, existe una brecha salarial entre varones y mujeres que, a nivel nacional, asciende a los 395,70 nuevos soles y que, solo en Lima, es de 532,89 nuevos soles. Es preciso resaltar que la mayor brecha se da entre las personas con formación universitaria; en efecto, los ingresos de las mujeres de este nivel representan el $56 \%$ de lo que perciben los varones: 1.161 nuevos soles versus 2.059,44 nuevos soles. Véase: Instituto Nacional de Estadística e Informática, Perú: Mercado Laboral Urbano y Género, Encuesta Nacional de Hogares 1999, INEI, Lima, 2000. 
Para el año 2000, la población de universitarios matriculados en las facultades de derecho se habría concentrado principalmente en la ciudad de Lima, con un $43 \%$-en solo doce de las cuarenta y cinco facultades de derecho de todo el país—, sobre un total de 41.192 alumnos al año 2000. El siguiente gran polo de concentración estaría constituido por las facultades de derecho del norte del país, con un 30\%. Las universidades del sur conformarían el 16\%, en tanto que las del Centro y de la Selva, en conjunto, alcanzarían el $11 \%$ restante (gráfico No 9). ${ }^{91}$ Estos datos, a la vez que pueden reflejar la mayor densidad poblacional de la capital, estarían asociados a los efectos del mayor desarrollo económico o de la mayor o menor incidencia de la pobreza por departamentos o regiones del país. Quizá no sea casual que, de acuerdo con el último informe sobre la pobreza del Instituto de Estadística e Informática (INEI), los departamentos de la zona sur y centro, junto con los de la Selva, son los más pobres del país, cuando la tasa de pobreza a nivel nacional es del $54.8 \%$. En esa dirección, en los departamentos de Huancavelica, Amazonas y Ucayali, así como de Loreto, Puno, Cusco, Apurímac, Ayacucho y Cajamarca las tasas de pobreza extrema superan el $40 \% .^{92}$

91 La clasificación propuesta para la elaboración de este gráfico comprende, en sus alcances, las siguientes universidades:

-Lima: Estatales: San Marcos, Federico Villareal, José Faustino Sánchez Carrión. Privadas: San Martín de Porres, Femenina del Sagrado Corazón, Inca Garcilaso de la Vega, Peruana de Ciencias Aplicadas, Alas Peruanas, Pontificia Universidad Católica del Perú, Universidad de Lima, Universidad Tecnológica del Perú y Universidad San Juan Bautista.

- Centro y Selva (Departamentos de Huánuco, Junín, Loreto y Ucayali): Públicas: Hermilio Valdizán, De la Amazonía Peruana, Peruana de los Andes, De Loreto y Nacional de Ucayali. Privadas: Privada de Huanuco y De Iquitos

- Norte (Departamentos de Ancash, La Libertad, Lambayeque, Piura, Tumbes y Cajamarca): Estatales: De Trujillo, De la Amazonía Peruana, De Piura, Nacional de Cajamarca, Pedro Ruíz Gallo y Santiago Antúnez de Mayolo Privadas: De Piura, De Chiclayo, San Pedro, Antenor Orrego, César Vallejo y Privada del Norte.

- Sur (Departamentos de Ica, Moquegua, Tacna, Apurímac, Ayacucho, Cusco y Puno): Estatales: San Antonio de Abad, San Agustín, San Luis Gonzaga, San Cristóbal de Huamanga, Del Altiplano y Jorge Basadre Grohmann. Privadas: Católica de Santa María, Andina Néstor Cáceres Velásquez, Andina del Cusco, Tecnológica de los Andes, De Moquegua, San Pablo de Arequipa y Privada de Tacna.

92 Javier Herrera, La pobreza en el Perú en 2001. Una visión departamental, Instituto Nacional de Estadística e Informática-Institut de Recherche Pour le Développment, Lima, 2002, p. 14. 


\section{Cuadro No 9}

Distribución geográfica de Alumnos de las Facultades de Derecho-Perú

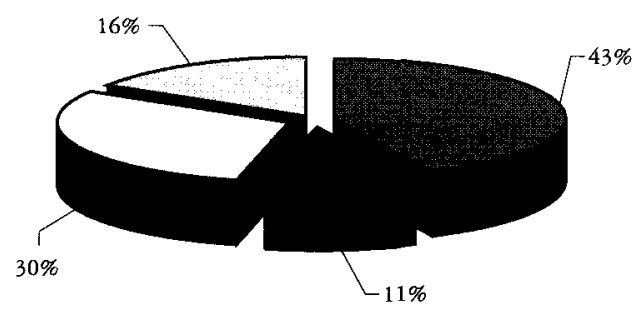

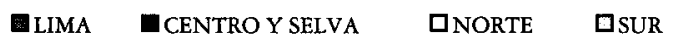

El mayor volumen de alumnos matriculados en Derecho tiene su origen en el universo de las facultades privadas. Este dato es marcadamente significativo en Lima, donde los estudiantes de las facultades de derecho de las universidades privadas constituyen el $79.25 \%$ del total, frente a un reducido $20.75 \%$, de las universidades públicas. Se observa la misma tendencia en el norte del país, del total de estudiantes de derecho, los matriculados en las facultades de las universidades privadas representan el 53.55\%. El fenómeno, sin embargo, no se repite en las facultades de las otras dos regiones del país, pues, en ambas, la población estudiantil de las facultades públicas sigue superando a la de las privadas (Cuadro No 10).

\section{Cuadro No 10}

Distribución geográfica de Alumnos de las Facultades de Derecho-Perú entre universidades públicas y privadas

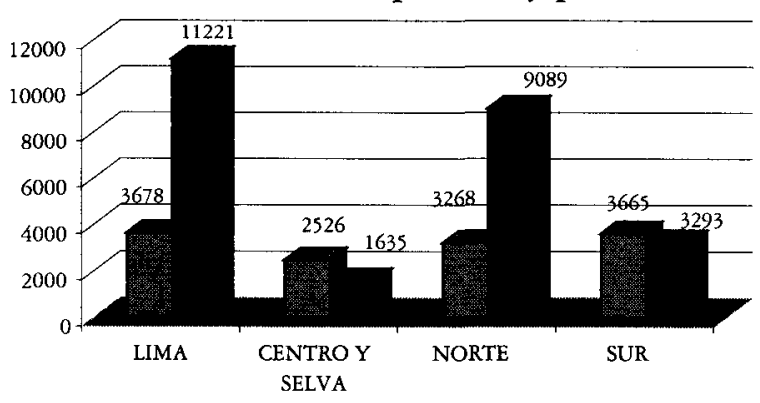

国 Públicas Privadas


La información anterior se complementa con la incorporación creciente de la población femenina a los estudios de derecho. En Lima, para el caso de las universidades públicas, los varones constituyen el $58 \%$ frente a un $42 \%$ de presencia femenina. En las universidades públicas del centro del país se mantiene la tendencia, aunque con ligera variación: los varones representan el $56 \%$ frente al $44 \%$ de la población femenina. Lo propio sucede con las universidades públicas del norte del país, donde los varones alcanzan el $54 \%$ frente al $46 \%$. Sin embargo, es el sur donde el cuadro de progresiva equiparidad en términos de acceso a los estudios de derecho entre hombres y mujeres se altera; así los varones constituyert el $63 \%$ frente a un minoritario $37 \%$ de población.

En las facultades de derecho privadas, la relación entre hombres y mujeres es muy ajustada para el caso de Lima, pues, mientras el $51 \%$ corresponde al sexo masculino, el universo femenino llega al $49 \%$. Un panorama muy semejante se observa en el caso de las universidades privadas del norte del país, donde los varones constituyen el $52 \%$ frente al $48 \%$ de la población femenina. En cambio, en las universidades del centro la diferencia es mayor a favor de la población masculina, que representa el $58 \%$ frente a un $42 \%$. Algo muy parecido ocurre en las universidades privadas del sur del país, donde las mujeres constituyen el $41 \%$ frente al $59 \%$.

\subsubsection{Los profesores de derecho: acceso, indicadores demográficos y forma- ción académica}

El ingreso a la docencia universitaria en el Perú está regido por la Ley Universitaria vigente ${ }^{93}$ y por los estatutos y reglamentos de cada institución. Existen tres grandes tipos de profesores universitarios, ordinarios, extraordinarios y contratados. Los primeros están en la carrera propiamente dicha, la misma que tiene tres niveles o categorías: auxiliar, asociado y principal. En líneas generales, el ingreso a la docencia se produce por sistemas de contratación o bien por concurso.

El ingreso por concurso comienza, normalmente, por la categoría de profesor auxiliar. Este concurso es de méritos ${ }^{94} \mathrm{y}$, en algunas universida-

93 La Ley No 23733, publicada el 17 de diciembre de 1983. Esta disposición legal ha sido objeto de diversas modificaciones.

94 Se trata de una calificación de los méritos académicos del postulante, hecha sobre la base de los documentos que así lo acrediten conforme aparezcan sostenidos en el currículum vitae. 
des - principalmente, en las públicas—, existe, además una evaluación de oposición. El profesor auxiliar deberá permanecer en esa categoría por lo menos tres años, al cabo de los cuales podrá presentarse al concurso de méritos correspondiente para el ascenso a la categoría de profesor asociado y, cinco años más tarde, para el ascenso a la categoría de profesor principal. En cada caso, los méritos se harán, en teoría, más exigentes, combinando la acreditación de estudios de postgrado, a nivel de maestrías y doctorados, con la publicación de investigaciones en las que el candidato haya participado efectivamente, además del valor asignado a su desempeño en la labor docente. ${ }^{95}$

Los profesores extraordinarios son fundamentalmente los Eméritos y honorarios, que reciben este título como señal de distinción y reconocimiento otorgada por la universidad.

Para el ingreso a la docencia en calidad de profesor contratado también puede ser necesario el participar en un concurso, pero esa no es la regla general. Este tipo de profesores desarrolla su labor docente principalmente por horas.

Un factor importante a tomar en consideración en el régimen docente es la dedicación. En general, los profesores de derecho - ya se trate de ordinarios o no- difícilmente se insertan en la docencia en regímenes laborales que impliquen más horas que las que exige el dictado. Y cuando esto ocurre -especialmente en las universidades públicas-, en los hechos la dedicación a tiempo completo o a medio tiempo implica solamente la atribución de mayor carga docente y, eventualmente, algunas asesorías o responsabilidades de tipo administrativo. El número de estos profesores suele ser limitado por la falta de recursos económicos y la ausencia de condiciones e infraestructura básica que permita el desarrollo de sus actividades en la facultad, con el consiguiente impacto negativo en la investigación.

En las facultades de derecho de las universidades privadas, el modelo de profesor a tiempo completo no está muy presente sino con limitaciones. En algunas universidades, aquellas que han enfilado su orientación

95 El sistema de evaluación más común suele sustentarse en las encuestas aplicadas a los estudiantes. Sin embargo, su uso no se extiende sino a algunas universidades privadas y el peso que se le asigna no es necesariamente el mismo. Recientemente, en la PUCP se está poniendo en marcha un sistema de evaluación más diversificado, que incluye, entre otras cosas, la evaluación por los pares. 
hacia las especialidades de tipo empresarial, el profesor a tiempo completo no forma parte necesariamente de su agenda, pues las preocupaciones institucionales están pendientes de gestar vínculos sólidos con abogados que tienen ya una inserción clara en el mundo laboral. En el caso de la Universidad de Ciencias Aplicadas lo dicho es bastante gráfico, pues su plana docente se conforma sobre la base de profesionales de estudios de abogados o entidades públicas. La imagen que este tipo de facultad forja, está asociada claramente al ejercicio profesional.

Es probable que en el caso de otras facultades de derecho, también privadas, la presencia de profesores a dedicación no esté siquiera imaginada. Es el caso de las universidades que nacieron con el proceso de desregulación del período fujimorista, en un contexto de precariedad institucional. En estas facultades, se constata déficit de docentes en general, tanto en número cuanto probablemente en experiencia y formación.

La excepción más clara en este aspecto es la Facultad de Derecho de la Pontificia Universidad Católica del Perú, en donde desde la reforma de fines de los años sesenta se ha mantenido el acuerdo básico de contar con una plana de profesores a tiempo completo (en la actualidad hay alrededor de quince), responsables de una mayor carga lectiva, pero también, en teoría, de impulsar la investigación. ${ }^{96}$

Para el año 2000 en el país se habrían contabilizado, aproximadamente, 19.586 profesores universitarios provenientes de universidades públicas, y 14.320 , de universidades privadas. ${ }^{97}$ De este universo, aproximadamente, 2.053 son profesores de derecho. Al igual que en el caso de los estudiantes, Lima concentra casi la mitad de docentes frente al resto de universidades del país. En términos globales, se estima que alrededor del $58 \%$ de los profesores de derecho de todo el país son contratados. La mayor parte de profesores (un estimado del $56 \%$ ) se encuentra fuera de Lima, mientras que el resto está en la capital.

El centralismo proyectado por lo dicho en el párrafo anterior, se combina con un predominio de la educación privada sobre la pública. Así, de una cifra aproximada de 2.053 profesores de derecho, el $68 \%$ correspon-

96 Desde la iniciativa generada en el marco de la reforma de la enseñanza en los años setenta, cuya responsabilidad estuvo a cargo del jurista y profesor arequipeño Héctor Cornejo Chávez, no se han producido otros impulsos institucionales orientados a desarrollar esta actividad de modo sostenido y con una agenda propia.

97 Información extraída de la página web http://www.inei.gob.pelperu.cifras. 
de a las universidades privadas y el $32 \%$, a las públicas. Más aún, para el año 2000, en el caso de Lima, los docentes provenientes de las facultades de derecho privadas habrían sumado alrededor del $76 \%$, frente a un minoritario $24 \%$ de las públicas.

Por otro lado, resulta revelador el panorama que presenta la relación entre varones y mujeres docentes. Para el año 2000, el predominio de la población masculina, en términos globales, es definitivo: más del $80 \%$ de los docentes son varones. En una universidad tan representativa como la Universidad Nacional Mayor de San Marcos, con ciento cinco profesores, la presencia de la mujer es aún menos significativa que en el promedio, pues, frente a un $85.72 \%$ de docentes varones, las mujeres apenas constituyen el $14.28 \%$ restante. En el caso de la Universidad Pedro Ruiz Gallo, de Lambayeque, la presencia de la mujer es marginal: de treinta y un profesores, veintiocho son hombres. La Universidad San Cristóbal de Huamanga es, todavía, mucho más gráfica, de veinte profesores, solo hay una mujer.

Entre las universidades que mayor incorporación de mujeres a la docencia han tenido en los últimos años, se pueden contar a la Pontificia Universidad Católica del Perú, que, de doscientos cuatro profesores, ciento sesenta y seis $(79,90 \%)$ son varones y cuarenta y uno $(20,09 \%)$, mujeres; asimismo, a la Universidad Peruana de Ciencias Aplicadas, que, de cincuenta y cinco profesores, cuarenta y cuatro $(80 \%)$ son hombres, frente a once (20\%). En buena cuenta, hay una relación de $80 \%$ a $20 \% .{ }^{98}$ Un caso paradójico es el de la Universidad Femenina del Sagrado Corazón-UNIFE, ubicada en la ciudad de Lima. Como su nombre lo indica, es una universidad para mujeres, pero sus docentes en derecho son principalmente varones; así, de un total de ochenta y un profesores, sesenta $(74,07 \%)$ son hombres, mientras que veintiún $(25,92 \%)$, mujeres.

Esta realidad puede ser un indicador de la forma cómo se encuentra segmentado el mercado laboral en el mundo profesional, pero también

98 Estos porcentajes han variado notablemente para el año 2002; por eso, vale la pena mencionarlo. La tendencia del predominio masculino se ha incrementado al punto que, en este momento, dicha Facultad de Derecho cuenta con noventa y seis profesores, ochenta y uno de los cuales son varones y quince, mujeres, es decir, casi el $85 \%$ son varones. $\mathrm{La}$ tendencia de estos dos últimos años es lo que llama la atención, pues el número de profesores varones al año 2000 se ha incrementado a casi el doble, de cuarenta y cuatro a ochenta y uno, en tanto que el número de mujeres solo ha aumentado de once a quince. 
refleja el imaginario «masculino» en el que se mueve mayoritariamente la enseñanza del derecho en el país.

Como expresión inevitable del centralismo, las únicas Facultades de Derecho que están en disponibilidad de exhibir la hoja de vida de sus docentes (es decir, la información sobre sus antecedentes académicos), son tres, todas privadas y situadas en la ciudad de Lima: la Universidad de Lima, la Pontificia Universidad Católica del Perú y la Universidad Peruana de Ciencias Aplicadas. Junto con ellas, como caso excepcional - pero explicable-, se encuentra también la Universidad Privada de Piura, que es la universidad del Opus Dei en el Perú. El centralismo se asocia, en este caso, a la posibilidad de acceso a los recursos y oportunidades para el desarrollo académico.

Sin embargo, aun en estos centros de enseñanza, el número de profesores con estudios de postgrado tiene cifras conservadoras. Por ejemplo, según información del año 2002, en la Universidad de Lima solo el 21\% de sus profesores (sobre un total de ciento sesenta y una) cuenta con estudios de postgrado (maestrías o doctorados). En el caso de la Universidad Peruana de Ciencias Aplicadas, esta cifra llega al 44\%, de un total de noventa y seis profesores, y, en la PUCP, se eleva al $57.7 \%$ del universo de doscientos setenta y nueve docentes. En la Universidad Privada de Piura, por su parte, el $32 \%$ de profesores (de un total de setenta y cuatro) ha realizado estudios de postgrado.

La presencia de la mujer en este contexto tiene sus peculiaridades. Puede concluirse, por un lado, que la proporción de mujeres con estudios de post-grado es bastante menor que la de los varones, tal como aparece en el siguiente cuadro, correspondiente a los estudios de maestría:

Cuadro No 11

Docentes universitarios de Derecho con grado de Magister (2002)

\begin{tabular}{|l|cc|cc|}
\hline Universidad & \multicolumn{2}{|c|}{ Varones } & \multicolumn{2}{c|}{ Mujeres } \\
\hline Universidad de Lima & 15 & $9 \%$ & 1 & $0,6 \%$ \\
Universidad Peruana de & 31 & $32 \%$ & 5 & $5 \%$ \\
Ciencias Aplicadas & & & & \\
Pontificia Universidad & 58 & $21 \%$ & 6 & $2 \%$ \\
Católica del Perú & 4 & $5 \%$ & 0 & $0 \%$ \\
Universidad de Piura & & & & \\
\hline
\end{tabular}


Se observan proporciones semejantes para el caso de los profesores que han obtenido el grado de doctor (Cuadro $N^{\circ} 12$ ).

Cuadro No 12

Docentes universitarios de Derecho con grado de Doctor (2002)

\begin{tabular}{|l|cc|cc|}
\hline Universidad & \multicolumn{2}{|c|}{ Varones } & \multicolumn{2}{c|}{ Mujeres } \\
\hline Universidad de Lima & 15 & $9 \%$ & 3 & $1,3 \%$ \\
Universidad Peruana de & 5 & $5 \%$ & 1 & $1,04 \%$ \\
Ciencias Aplicadas & 5 & & & $1 \%$ \\
Pontificia Universidad & 29 & $10 \%$ & 2 & $8 \%$ \\
Católica del Perú & 12 & $16 \%$ & 6 & \\
Universidad de Piura & & & & \\
\hline
\end{tabular}

Si bien es posible establecer alguna relación de origen entre estas diferencias - es decir, la baja proporción de docentes mujeres- en el conjunto de facultades de Derecho, hay que admitir que las diferencias se acentúan notablemente en el universo del postgrado para cada universidad; sin embargo, quizás como contraste, no deja de llamar la atención el mayor grado de movilidad hacia el extranjero que muestran las docentes mujeres. En efecto, las profesoras demuestran tener, en proporción, un mayor grado de movilidad para realizar sus estudios de postgrado en el extranjero frente a los varones: en la Universidad de Lima, por ejemplo, el 50\% de mujeres con estudios postgrado los realizó en universidades del extranjero, en tanto que solo el $43.3 \%$ de hombres hicieron lo propio. En la Pontificia Universidad Católica, el $41 \%$ de mujeres efectuó sus estudios de postgrado en el extranjero, frente a un $37 \%$ de profesores varones. La cifra resulta contundente en los casos de la Universidad Peruana de Ciencias Aplicadas y de la Universidad de Piura, pues, en ambas, el 100\% de mujeres cursó sus estudios de postgrado en el extranjero, frente al $75 \%$ de los varones, para el caso de la primera, y el $89 \%$, para el caso de la segunda.

El tipo de universidad donde se realizan los estudios de postgrado es un factor importante en la articulación de los valores que prefiguran el perfil docente. Se convierte en un indicador de ajuste para la definición de la política educativa de la institución, y, en ese sentido, imprime una cierta perspectiva en la formación y en el propio perfil profesional de los 
estudiantes de Derecho. Esta perspectiva se observa con claridad en la Universidad Privada de Piura por el un profundo vínculo entre el perfil de sus estudios de postgrado (la Universidad de Navarra), con sus compromisos ideológicos y religiosos, pues se trata de la universidad del Opus Dei.

\section{Los titulados en Derecho}

La alta densidad poblacional de estudiantes de derecho al año 2000 se refleja inevitablemente en un elevado número de titulados. Del universo de titulados de todas las carreras profesionales, que bordea los 23.139 para las universidades públicas, y los 15.405 , para las privadas, ${ }^{99}$ los de Derecho constituyen alrededor del $8 \%$.

En este caso, la relación entre varones y mujeres tiene una diferencia acentuada a favor de los primeros, que contrasta con la tendencia hacia el equilibrio entre el nivel de postulantes y de alumnos matriculados. En efecto, los hombres constituyen el $59 \%$, frente al $41 \%$ de la población femenino.

El alto número de graduados que se registra para el año 2000 tiene relación con el hecho de que, para el mismo año, Derecho es la segunda carrera más poblada del país. Este dato contrasta con las dificultades que implica la inserción en el mercado laboral del país. A propósito de ello, la encuesta sobre «Imagen de las Carreras", efectuada por el Grupo Apoyo en septiembre de 2000 , considera que Derecho se encuentra en el quinto lugar, en términos de posibilidades, entre las carreras con las que se consigue trabajo más rápido. Por encima se hallan Administración de Empresas, Ingeniera Informática y de Sistemas, Contabilidad e Ingeniería Industrial. ${ }^{100}$ No obstante, refuerza, más aún, esta idea, el cuadro sobre la percepción de la carrera con más desempleados, donde Derecho ocupa el primer lugar. ${ }^{101}$

No se puede dejar de valorar, en este contexto, la presencia del bachillerato automático. Se trata del Decreto Legislativo No $739^{102}$, en cuya

99 Información extraída de la página web http://www.inei.gob.pe.

100 Apoyo, opinión y mercado. Calidad de servicio en Educación Superior-PUCP. Lima, 2000. p. 24.

101 Ibid., loc. cit.

102 Publicada en el diario oficial «El Peruano», el 12 de noviembre de 1991. Esta norma modificó el artículo $22^{\circ}$ de la Ley $N^{\circ} 23733$, Ley Universitaria. 
virtud el régimen fujimorista suprimió la obligación de elaborar la tesis para obtener el grado académico de bachiller, requisito previo a la licenciatura. El bachillerato, se dice, por ello, se obtendría en forma automática y vinculada a la condición de egresado.

El impacto del «bachillerato automático" se observa con mucha claridad en el caso de la PUCP. En efecto, a partir del año 1992 se produjo un salto impresionante: de una tasa de crecimiento anual promedio de $5,76 \%$, entre los años 1980 y 1991, se pasó a una tasa de crecimiento anual promedio de 22,26\%, entre los años 1992 y 2002.

\section{Reflexión final}

La enseñanza del derecho no parece estar desvinculada del proceso político en el Perú. Si históricamente la república se gestó por una élite que pudo expandir sus intereses y confundirlos con la dimensión institucional de lo público (asociado en la ideología de aquella, al Estado), se entiende entonces que el formalismo jurídico debía operar como estrategia de razonamiento para justificar la generalidad de dichas instituciones y la legitimidad del sistema legal y político como conjunto.

Es probable que la enseñanza en las facultades de derecho retroalimentara esta visión de lo jurídico en un contexto político de dependencia, centralismo y exclusión social, cuyos arribos no pocas veces concluyeron en procesos de violencia política. El derecho, en esa lógica, pudo servir para auspiciar la incongruencia, invisibilizar, relativizar o enfatizar ${ }^{103}$ las realidades que estaban en juego.

Esta forma de entender y usar el derecho - a veces como instrumento de impunidad-, fortalecida por la debilidad institucionalidad y la cultura del formalismo, hace parte de un contexto en el que la información sobre el sistema no es necesariamente transparente y en donde se percibe una ausencia de control básico sobre la calidad educativa de las facultades de derecho. Es un escenario que se presta con enorme facilidad para articular en forma eficaz las «necesidades» de los potenciales postulantes; más aún, sugiere que la relación entre el crecimiento de la demanda y el incremento de la oferta de los estudios del derecho en los últimos años, no resulta necesariamente de la ampliación del mercado profesional.

103 Pierre Bourdieu, "The Force of Law: Toward a Sociology of the Juridical Field», en: Hastings Law Review, No 38, 1987, p. 38. 
Todo lo anterior parece indicar, más bien, que el uso subliminal del poder y su relación con el derecho ha sido aprovechado en un ámbito de desregulación pernicioso, matizando el impacto que la educación superior tiene como mecanismo de ascenso social en el Perú. Este factor puede estar presente entre las razones que explican la paradoja del crecimiento de la demanda en una carrera profesional que presenta las mayores probabilidades de desempleo en el país.

A propósito del escenario en el que se mueve la educación superior en el Perú, cabe recordar que ésta ha sido el componente histórico de una política estatal de desatención, maltrato y hostigamiento, donde la desregulación constituye una modalidad eficiente de todo ello con consecuencias inciertas, sino negativas en la calidad de la educación. En esta realidad, las facultades de derecho han tenido un lugar importante, pues, como se sabe, una facultad de derecho no requiere inversión significativa de recursos, comparativamente hablando; se necesita un sujeto que transmita información y esto se facilita aún más si la lógica que gobierna la pedagogía es la "cátedra magistral», que parece ser la que predomina en la mayor parte de las facultades de derecho. Se abre, entonces, una «ventana de oportunidad" que "facilita» las cosas para el estudiante, pues su esfuerzo estará siempre calculado en función de la cantidad de información que deba memorizar y luego repetir en las evaluaciones.

La oferta en esta realidad, alienta el interés, pues aprovecha en forma audaz la imagen que genera la profesión legal y su relación con el poder, sin medir las consecuencias de este proceso en el ámbito del ejercicio ético de la profesión. Es ingenuo negar que ambos, la formación y el sentido que adquiere la práctica legal, forman parte de una cadena de transmisión que no se rompe con facilidad. Los abogados que logran insertarse en el mundo laboral lo hacen siempre en espacios de toma de decisiones; por ello, su contribución a la forma cómo se construye la política, en tanto acto cultural, es claramente reconocible y lleva consigo, la incidencia de su propia formación jurídica.

En otro extremo del problema, los cambios operados en el sistema de enseñanza del derecho, por lo menos, los más notorios, han estado orientados a mantener el vínculo con lo acontecido en el escenario polííco institucional del país. Ese fue el sentido de la reforma iniciada en la Pontificia Universidad Católica del Perú en los años sesenta y se ha mantenido en el discurso hasta hoy. Lo propio ocurre con la innovación en contenidos y metodologías introducida por la Universidad Peruana de 
Ciencias Aplicadas. Y, a decir verdad, no hay en el espacio universitario más elementos a la vista que proyecten la idea de cambios o reformas en la enseñanza del derecho.

En el caso de la PUCP, el movimiento de los sesenta tuvo dos grandes ejes centrales en la base del discurso inicial, uno orientado a cuestionar y replantear la concepción del derecho mismo (como instrumento de cambio social), y el otro, a introducir, como factor coadyuvante, cambios en la parte metodológica. El primero no pasó de ser una incursión utópica de la que nadie habla más. En todo caso, no con la fuerza y cobertura institucional que tuvo en aquel momento. Es el segundo eje el que ha logrado sobrevivir como discurso y praxis, con la dificultad y el riesgo que fueran advertidos en su momento, como parte del discurso crítico del movimiento reformista de fines de los setenta. Se sostenía en aquella oportunidad que la reforma de los estudios del derecho, no se resumía a la pregunta sobre el método, sin modificar la concepción del derecho, pues ello, en lugar de mejorar las condiciones de la enseñanza, podría, más bien, propiciar un fortalecimiento de los obstáculos al cambio. ${ }^{104}$

Es un desafío, sin duda, lograr el equilibrio que impida reducir la reforma de la enseñanza legal a la aplicación del método activo, y no dejar de cuestionar la idea del derecho, con el compromiso ético que ello implica. Y se trata de un reto, pues involucra apostar por la formación de los valores democráticos de quienes tendrán decididamente un papel clave en la vigencia de los mismos. En otras palabras, la formación en destrezas es esencial para romper el círculo cerrado de la educación exegética, pero si ésta no va acompañada de convicciones y valores, su resultado y quienes se formen en ellas siempre podrán ser aprovechados por las posiciones que se presentan como neutrales pero que suelen emparentarse con las dictaduras y los modelos autoritarios.

Romper el círculo cerrado de esa educación exegética implica abrir un camino diferente para dejar atrás la herencia de imposición, intolerancia y desigualdad. Implica poner la agenda de las prioridades institucionales, de los derechos y su dimensión pública y ciudadana, en la base del aprendizaje del derecho. Quizá la clave esté en asumir una "posición original»-en el sentido de Rawls - sabiendo que todos aceptamos y nos comprometemos a aceptar las reglas que van a permitir desarrollarnos y desarrollar

104 Fernando de Trazegnies. "La enseñanza del derecho como actividad subversiva", op. cit., pp. 50-51. 
nuestras instituciones públicas, las que queremos construir en un sistema democrático. Por lo demás, este es un discurso ético y normativo no distante del que justifica las instituciones legales, que en este caso va provisto del peso asignado a la responsabilidad institucional y pública de las facultades de derecho.

La ruta que parece diseñarse con amplitud a través de esta incidencia en lo público, desde el punto de vista de la metodología tanto como en el ámbito de los contenidos, se convierte en un medio y una estrategia de aprendizaje. En cuanto al método, porque permite trabajar con todos los instrumentos, productos, escenarios y vestigios de lo legal. Para descubrir las razones y las sinrazones que están detrás, en la medida que son parte de un discurso orientado a crear mecanismos de interacción institucional y convivencia humana. Desde el punto de vista de los contenidos, debe permitir explorar las distintas teorías como enfoques en permanente evolución, como esfuerzo argumentativo que se redimensiona por efecto de las demandas sociales, de las prioridades morales, tanto como cuando el intérprete asigna un significado normativo a la ley.

La ausencia de réplicas o esfuerzos de reforma autónomos en otras universidades del país, principalmente en las públicas, puede registrar formar distintas de vinculación entre las facultades y la dinámica política. En todo caso, no debe pasarse por alto, el alto grado de politización ideológica - con grandes dosis de dogmatismo-, especialmente de la universidad pública en los años setenta, que, en buena cuenta, paralizó el esfuerzo por generar un discurso crítico al derecho desde las propias facultades. La historia posterior está fuertemente tomada por la crisis institucional del país y, en ese escenario de crisis económica y violencia política, los esfuerzos en estas universidades, antes que a la reforma, estuvieron orientados a gestar mecanismos de supervivencia institucional.

La transición política como proceso dinámico para crear condiciones de viabilidad y convivencia social en el país, exige de parte de todas las entidades de la sociedad civil un gran nivel de responsabilidad y compromiso. ${ }^{105} \mathrm{Y}$ el papel de los abogados resulta siendo clave en todo este proceso. Su presencia en los centros y espacios de toma de decisiones los convierte, como ya se dijo, en actores fundamentales del modo de ser

105 Juan Linz y Alfred Stepan, Problems of Democratic Transition and Consolidation. Southern Europe, South America, and Post-Communist Europe, John Hopkins University Press, Baltimore, 1996, p. 5 y ss. 
institucional. Las facultades de derecho tienen entonces una responsabilidad incluso mayor, pues en sus manos está la misión de formar a quienes operan el sistema institucional de modo privilegiado. Negar esta realidad o adelgazarla con un discurso que pretende agotar la responsabilidad de las escuelas de derecho en la formación en destrezas, no solo resulta inconsistente con la idea de contribuir al desarrollo de las instituciones democráticas, sino que, en esa misma dirección, será difícil crear las condiciones para propiciar entornos que faciliten el ejercicio de la profesión legal en términos de eficiencia. En realidad, sin instituciones democráticas léase reglas claras e instituciones transparentes-, definidas por los principios de justicia e igualdad, se estrechan los márgenes para lograr eficiencia a la hora de medir la inversión en tiempo y recursos de cualquier operador. Así ocurre en los escenarios de corrupción, trabas burocráticas, tráfico de influencias, arbitrariedad o falta de justificación en los sistemas de toma de decisiones.

De otro lado, nada de lo dicho se sitúa a espaldas de la necesidad de aprovechar eficazmente las herramientas que provee la tecnología. El cambio y la transformación deben ser el resultado articulado de la innovación y la realidad, pues se trata de valorar la identidad propia como instrumento para conocer mejor las necesidades que deberán transformarse. Enfrentar el problema de la reforma de la enseñanza en el ámbito de la realidad local y en el escenario de la globalización no supone diluir lo propio para transplantar enfoques o instituciones extranjeras. Por cierto, esta es una práctica ya conocida y con predicamento entre las propias visiones tradicionales del derecho, que, al final, terminaron devaluando las versiones importadas, creando una atmósfera académica cerrada, sin vínculo con el país, reduciendo el ámbito de lo jurídico al estudio de las normas escritas con métodos exegéticos, ajenos a la posibilidad de desarrollar ningún tipo de crítica relativa a la eficacia del derecho.

Este último punto se conecta con la necesidad de propiciar consensos mínimos en torno a los mecanismos eficaces de control para la existencia de las facultades de derecho. Ello requiere un fuerte nivel de compromiso institucional para cumplir con ciertas condiciones básicas, como la presencia de profesores en número adecuado y con la formación esencial, una infraestructura razonable de recursos bibliográficos y tecnológicos, mecanismos de formación docente, y planes de estudios articulados a las demandas institucionales de la democracia, dentro de la cual se encuentra el mercado profesional. 
Seguir apostando al modelo «desregulado» de algunas universidades privadas, cuyos males también se deslizan en el escenario de las públicas, quizá sirva para cubrir temporalmente ciertos vacíos de la acción estatal, generando expectativas irreales de empleo y ascenso social. Pero el efecto irremediable será el incremento del desempleo, el deterioro de algunos espacios profesionales del ejercicio legal, y el robustecimiento de un modelo potencialmente proclive a la discriminación, con el impacto negativo que esto supone, debido al papel institucional y político que desempeña la profesión legal. 